ORNL/TM2001/97

LBNL-47983

\title{
Load As a Reliability Resource in Restructured Electricity Markets
}

\author{
J. D. Kueck ${ }^{1}$ \\ B. J. Kirby ${ }^{1}$ \\ J. Eto ${ }^{2}$ \\ R. H. Staunton ${ }^{1}$ \\ C. Marnay $^{2}$ \\ C. A. Martinez ${ }^{3}$ \\ C. Goldman ${ }^{2}$
}

June 1, 2001

1. Oak Ridge National Laboratory, Oak Ridge, Tennessee

2. Lawrence Berkeley National Laboratory, Berkeley, California

3. Southern California Edison, Rosemead, California

\author{
Prepared by \\ OAK RIDGE NATIONAL LABORATORY \\ Oak Ridge, Tennessee 37931-6285 \\ Managed by \\ UT-BATTELLE, LLC \\ for the \\ U. S. DEPARTMENT OF ENERGY \\ under contract DE-AC05-00OR22725 \\ and \\ LAWRENCE BERKELEY NATIONAL LABORATORY \\ Berkeley, California 94720 \\ Managed by \\ UNIVERSITY OF CALIFORNIA \\ for the \\ U. S. DEPARTMENT OF ENERGY \\ under contract DE-AC03-76SF00098
}


This report was prepared as an account of work sponsored by an agency of the United States government. Neither the United States government nor any agency thereof, nor any of their employees, makes any warranty, express or implied, or assumes any legal liability or responsibility for the accuracy, completeness, or usefulness of any information, apparatus, product, or process disclosed, or represents that its use would not infringe privately owned rights. Reference herein to any specific commercial product, process, or service by trade name, trademark, manufacturer, or otherwise, does not necessarily constitute or imply its endorsement, recommendation, or favoring by the United States government or any agency thereof. The views and opinions of authors expressed herein do not necessarily state or reflect those of the United States government or any agency thereof. 


\section{CONTENTS}

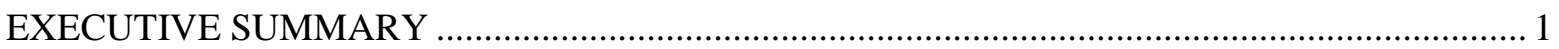

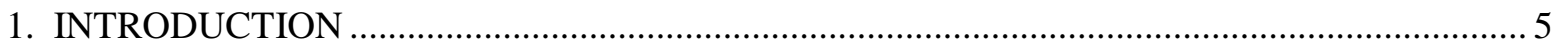

2. ANCILLARY SERVICES AND END-USE TECHNOLOGY ASSESSMENT ......................... 7

2.1. Ancillary Services And Their Response Time Requirements............................................ 7

2.2 Survey of Present Load Participation Methods and Markets ............................................. 12

2.3 Application To SCE Load Management Programs ............................................................ 14

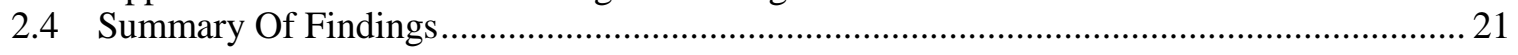

3. PROGRAM EXPERIENCE - PAST AND PRESENT ............................................................ 23

3.1 Review Of U.S. Utility Load Management Programs ............................................. 23

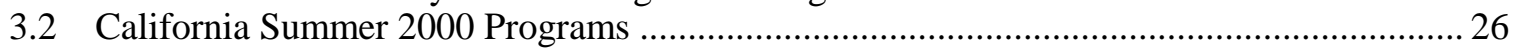

3.2.1 California ISO participating load and demand relief programs ...............................26

3.2.2 California IOU Summer 2000 interruptible load programs ........................................29

3.3 ISO New England Load Management Program …............................................................ 33

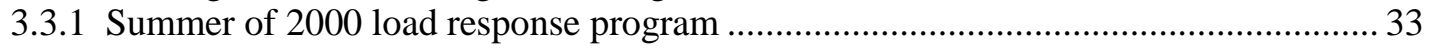

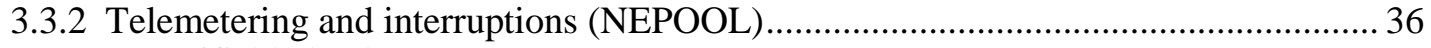

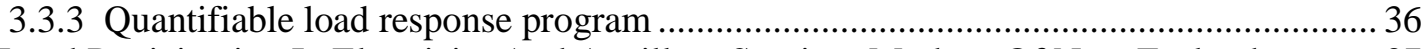

3.4 Load Participation In Electricity And Ancillary Services Markets Of New Zealand............. 37

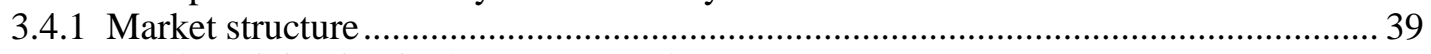

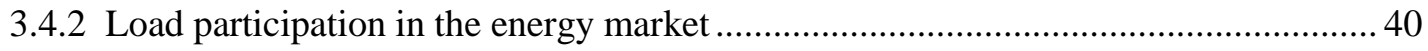

3.4.3 Load participation in ancillary services markets ................................................ 41

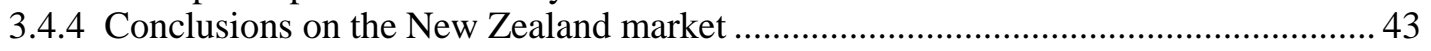

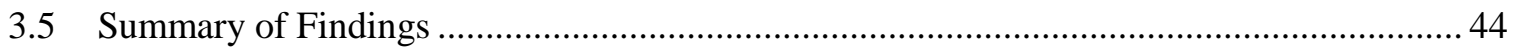

4. LOAD METERING, COMMUNICATION, AND RESPONSE

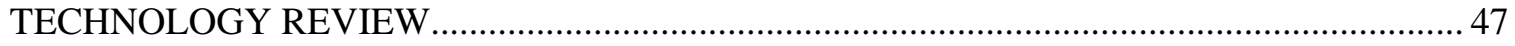

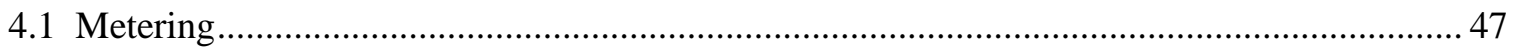

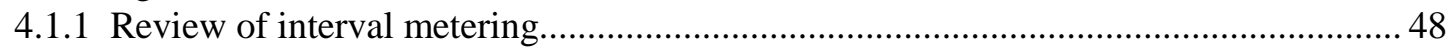

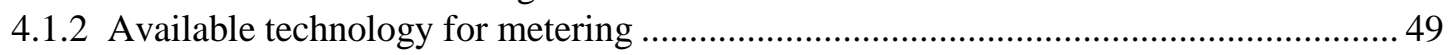

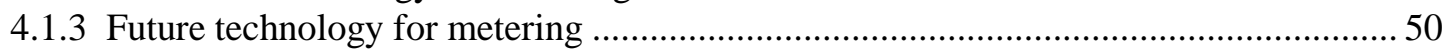

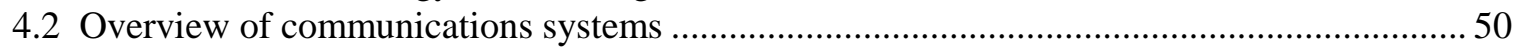

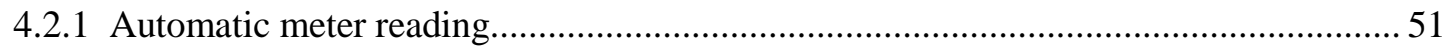

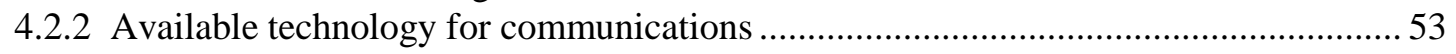

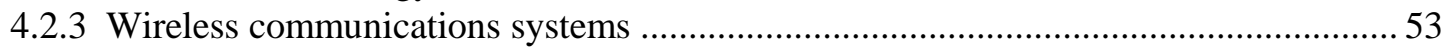

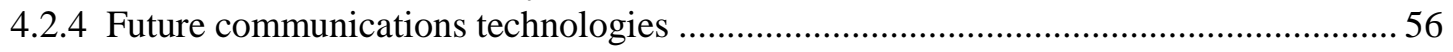

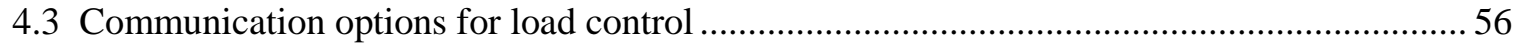

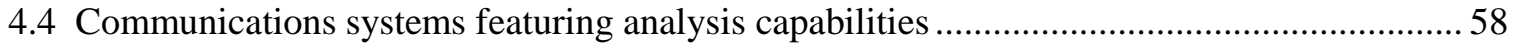

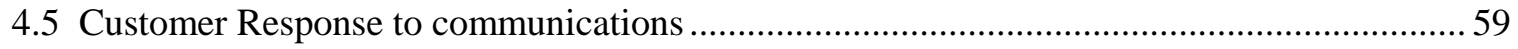

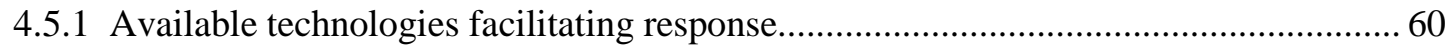

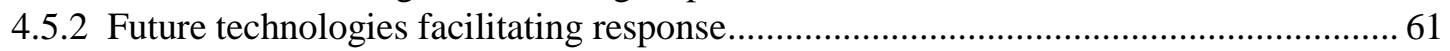

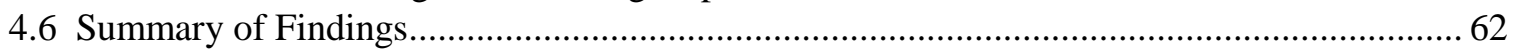




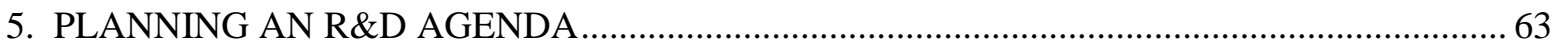

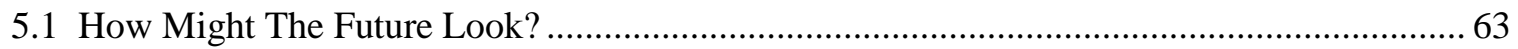

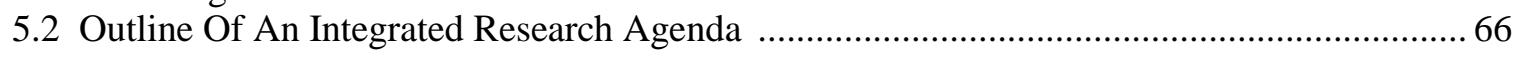

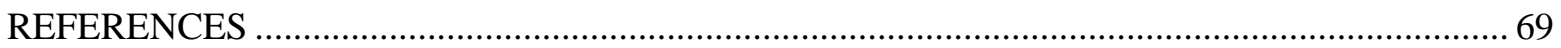

\section{List of Figures}

1-1 Current relationship between electricity supply and demand............................................... 5

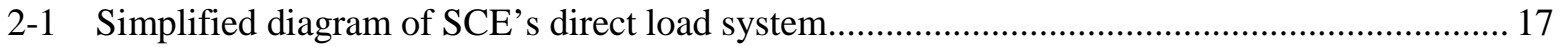

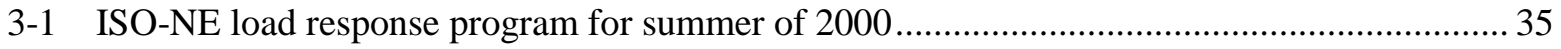

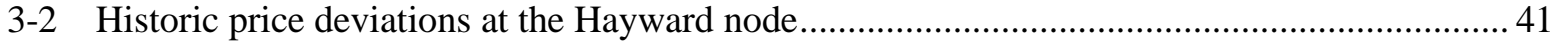

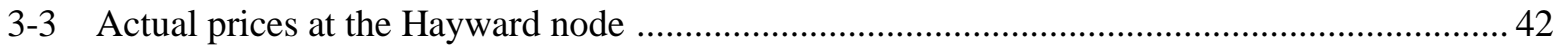

\section{List of Tables}

2-1 Possibilities for End Use Methods and Technologies for Providing

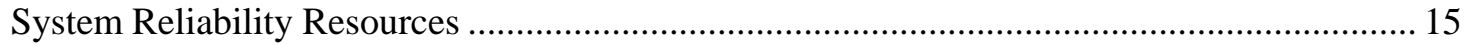

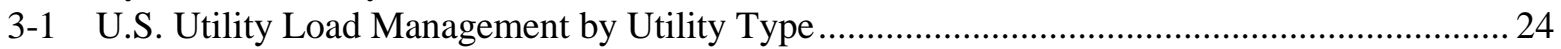

3-2 U.S. Utility Load Management by Customer Class ............................................................. 25

3-3 U.S. Utility Load Management by Region ..................................................................... 25

3-4 Largest Utility Load Management Programs (1998) .............................................................. 26

3-5 California ISO Demand Relief Program Operation - Summer 2000 .................................... 28

3-6 California ISO Demand Relief Program Performance - Summer 2000................................ 28

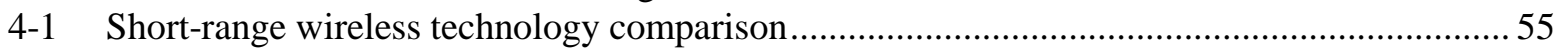

5-1 Typical residential load energy consumption and potential for price response........................ 65 


\section{EXECUTIVE SUMMARY}

Recent electricity price spikes are painful reminders of the value that meaningful demand-side responses could bring to the restructuring US electricity system. Review of the aggregate offers made by suppliers confirms that even a modest increase in demand elasticity could dramatically reduce these extremes in price volatility. There is a strong need for increased customer participation in markets to enhance system reliability and reduce price volatility. Indeed, allowing customers to manage their loads in response to system conditions might be thought of as the ultimate reliability resource.

Most would agree that meaningful demand-side responses to price are the hallmark of a well-functioning competitive market. Yet, in today's markets for electricity, little or no such response is evident. That is, today's markets are incomplete; they represent only half of what a truly competitive market requires.

The reason is simple: customers currently do not experience directly the time-varying costs of their consumption decisions. Consequently, they have no incentive to modify these decisions in ways that might enhance system reliability or improve the efficiency of the markets in which electricity is traded. Increased customer participation is a necessary step in the evolution toward more efficient markets for electricity and ancillary services.

This scoping report provides a three-part assessment of selected aspects of growing interest in enhancing the ability of customer's load to participate in competitive markets. The report focuses specifically on the current and potential future role of customer loads as system reliability resources. The critical policy and regulatory issues that must be addressed in order to implement increased customer price response are beyond the scope of this report.

The scoping effort begins by first evaluating the extent to which customer loads might be able to provide electricity reliability or ancillary services. The study defines ancillary services and then conducts two assessments. The first assessment offers general considerations for a variety of ways one might examine customer loads as reliability resources (e.g., aggregated into formal programs, individual end-uses, individual technologies, etc.). The second assessment systematically reviews aspects of a large utility's direct load control program with respect to the requirements of each ancillary service.

Some key findings relating to ancillary services are as follows:

1. Many controllable customer loads appear well suited to provide some, but not all, ancillary services, notably system reserves such as spinning, non-spinning, and replacement reserve.

2. Some, such as water pumping by municipal or other utilities, potentially represent significant reliability resources; it is estimated that water pumping accounts for $2 \%$ of US electricity consumption.

3. A key, yet currently under-developed, enabling technology that will allow distributed generation to provide certain ancillary services is the power electronic interface between the distributed generation and the grid.

4. Utility load management programs, such as direct load control, represent already well-organized efforts to deploy large blocks of customer loads as system reliability resources. 
The second phase of the assessment expands this last finding into a more formal survey of a variety of programmatic approaches in which load has been called on as a system reliability resource. The assessment focuses on programs triggered by system conditions (e.g., forecast reserves fall below a threshold), and also one program triggered by a price signal (e.g., a real-time price). The assessment begins by considering the magnitude of the national reliability resource represented by existing utility load management programs. It then reviews the recent experience of several programs in emerging competitive markets: (a) the California ISO's Demand Relief and Participating Load programs; (b) Interruptible or load programs in California, which are operated in conjunction with California ISO's programs; and (c) the New England ISO's Load Management program. The final sub-section reviews the New Zealand experience with load management, which is a mature example of the integration of customer loads with electricity system reliability management.

The following summarizes key observations regarding past and current load management programs:

1. The underlying communication, control, and metering technologies in existing utility load management programs, as well as potentially the program designs and operational procedures, themselves, represent important, yet currently un-appraised (and potentially undervalued), reliability assets for future competitive markets.

2. The California ISO's two load programs, called Ancillary Services Load Program (also referred to as the Participating Load Program), and the Demand Relief (DR) Program fell substantially short of targeted participation in the Summer of 2000. A key technical barrier for the Participating Load program was CAISO's stringent telemetry (4-second) requirements. A key institutional barrier for both programs was the limited time over which the programs were developed and implemented (programs were first announced in Jan./Feb. 2000).

3. Existing utility interruptible load programs already embody many characteristics that may be incorporated into future reliability-motivated load participation programs: (1) interruptions are triggered by a signal from the utility in response to system conditions; (2) customers have substantial discretion over the manner in which load is shed, in some cases including reliance on distributed generation (in contrast to direct load control programs that turn off designated pieces of end-use equipment); (3) customers at times have discretion over whether or not to interrupt at all; and (4) the utility already has procedures in place to verify interruption. Yet, there are significant unresolved technical and institutional issues, including observability (telemetry) issues on the one hand and the scope of utilities' retail activities (including operation of load management programs) in competitive markets on the other.

4. ISO-NE's pilot programs and short-term load management solutions over time have had mixed results. A key design feature of the latest program allows the retail customer to make an informed choice on whether to respond to prices in the market.

5. In New Zealand, use of load shedding as a fast response ancillary service has a decade-long history. However, the ancillary service being provided, the low incidence of interrupts, and the automatic nature of its initiation based on system frequency does not have parallels currently in U.S. markets. Loads also participate in New Zealand's energy markets as a result of a procedure that, in California terms, is equivalent to the scheduling coordinator self-dispatching load to repeatedly revise its schedule.

\footnotetext{
${ }^{1}$ During the preparation of this report, the 4-second requirement was reduced in order to mitigate this barrier.
} 
The third phase of the assessment examines the status of the underlying metering, communication, and control technologies used to effect customer responses. The focus is on cataloging the technologies and approaches currently in the market. The scope of this review is somewhat broader than that covered in earlier sections of this report in that it includes technologies which would be applied to either price-based or system condition-based programs for engaging customer loads.

Key findings regarding communications and control technologies are as follows:

1. A wide array of advanced power meters is now available that provide reactive/apparent power, time of use data (i.e., in segregated time frames), interval date (i.e., KW vs time), and special communications features that operate via phone, radio, or power lines;

2. Wireless data communication systems for metering, load data, control functions, etc. provide adequate speed and advantages of universal communications interfaces, automatic reconfiguration as new devices are added, and security features such as data encryption and user authentication;

3. The Internet and local load control by the customer empowers the customer by giving him authority (and the necessary information) to interrupt based on his preferences and market conditions;

4. Available load control communications systems feature advantages including, (a) using the PC as a communications and control center, (b) interrogating meters and storing data, (c) using the Internet to provide day ahead curtailment prices, and (d) analysis capabilities; and

5. Customer response can be aided by systems that provide real time prices, both automatic and manual control, and control of set points throughout a facility that respond to dynamic price signals.

The final section of the report provides a vision of how the future might look and uses it to outline a program of needed R\&D to increase the role of customer loads as system reliability resources. Key elements of this research program include:

1. Addressing the information needs and control requirements of system operators;

2. Repositioning existing utility load management assets;

3. Accelerating the transfer of emerging program experiences;

4. Pioneering promising new program design concepts;

5. Incorporating grid reliability considerations into the design and operation of end-use technologies; and

6. Disseminating technology and programmatic solutions through demonstrations.

Tight markets for capacity, excessive price volatility, and increasingly frequent reliability events are all signs of an electricity system under stress. Unlocking the tremendous potential of customer's loads ought to be a core element of strategies to relieve these stresses. Indeed, enabling meaningful customer participation is a necessary ingredient for the ultimate realization of truly competitive and efficient markets for electricity. This paper has surveyed current experience and outlined needed research toward this end. 


\section{INTRODUCTION}

Recent electricity price spikes are painful reminders of the value that meaningful demand-side responses could bring to the restructuring US electricity system. Review of the aggregate offers made by suppliers confirms that even a modest increase in demand elasticity could dramatically reduce these extremes in price volatility. There is a strong need for dramatically increased customer participation in these markets to enhance system reliability and reduce price volatility. Indeed, allowing customers to manage their loads in response to system conditions might be thought of as the ultimate reliability resource.

Most would agree that meaningful demand-side responses to price are the hallmark of a well-functioning competitive market [1]. Yet, in today's markets for electricity, little or no such response is evident. The reason is simple: customers currently do not experience directly the time-varying costs of their consumption decisions. Consequently, they have no incentive to modify these decisions in ways that might enhance system reliability or improve the efficiency of the markets in which electricity is traded. Increased customer participation is a necessary step in the evolution toward more efficient markets for electricity and ancillary services.

Figure 1-1 illustrates how, at high levels of demand, supply is increasingly inelastic leading to very high market clearing prices for electricity. That is, today's markets are incomplete; they represent only half of what a truly competitive market requires.

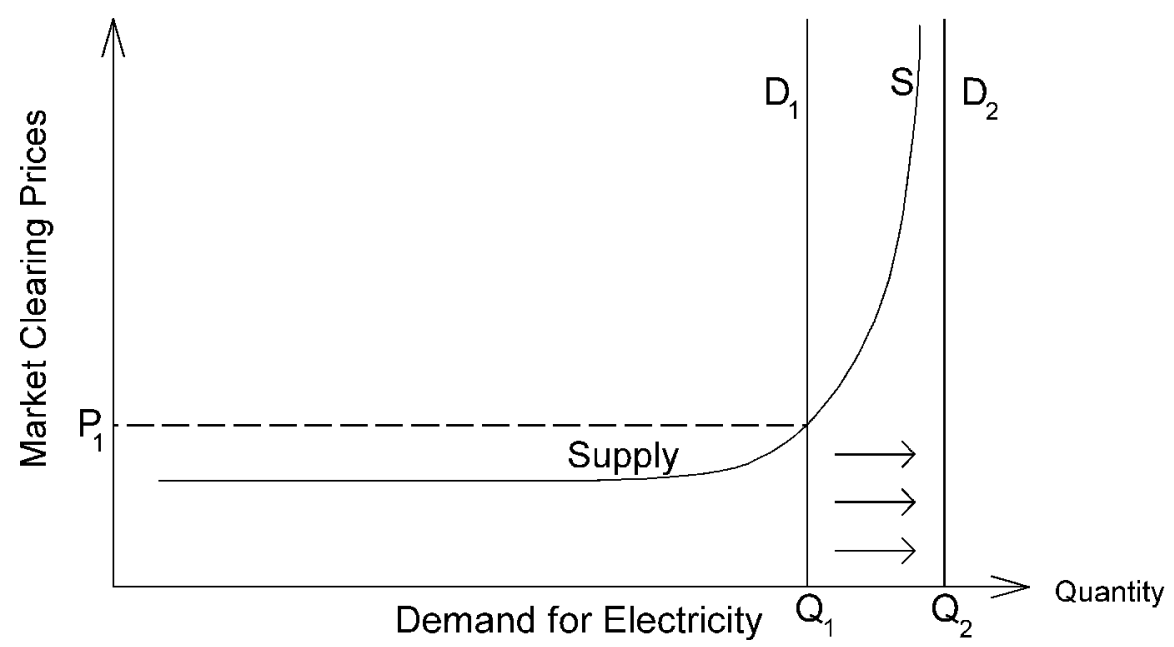

Fig. 1-1 Current relationship between electricity supply and demand

This scoping report provides a three-part assessment of the current status of efforts to enhance the ability of customer's load to participate in competitive markets with a specific focus on the role of customer loads in enhancing electricity system reliability. First, this report considers the definitions of electricityreliability-enhancing ancillary services (Section 2) and a preliminary assessment of the ability of customer's loads to provide these services. Second, is a review a variety of programs in which load has been called on as a system reliability resource (Section 3). These experiences, drawn from both past and current utility and ISO programs, focus on programs triggered by system condition (e.g., forecast reserves fall below a threshold), rather than those triggered by price (e.g., real-time prices). Third, the 
report examines the status of the underlying metering, communication, and control technologies required to enable customer loads to participate in competitive electricity markets (Section 4). Following the three-part assessment, we offer preliminary thoughts on directions for future research (Section 5). 


\section{ANCILLARY SERVICES AND END USE TECHNOLOGY ASSESSMENT}

This scoping effort begins with an evaluation of the extent to which customer loads might be able to provide electricity reliability or ancillary services. We first define ancillary services and then conduct two assessments. The first assessment offers general considerations for a variety of ways one might examine customer loads as reliability resources (e.g., aggregated into formal programs, individual end-uses, individual technologies). The second assessment systematically reviews aspects of a large utility's direct load control program with respect to the requirements of each ancillary service.

\subsection{Ancillary Services and Their Response Time Requirements}

This section discusses ancillary services that may be provided by loads and also address the requirements imposed by the various ancillary services on loads that wish to provide the services. The discussion will mainly focus on the time requirement and other needs as they apply to the specific service. In general, dispatch communications - to de-energize or energize the load - need to be accomplished only in the range of a few minutes, similarly for bids when load services are being traded on the market. The amount of information that must be transferred for an ancillary service transaction is typically only a MW amount and a price. In cases where an existing contract specifies the MW amount, for example, a large department store may dim lighting and cut $100 \mathrm{~kW}$, the amount may not even need to be communicated, just the agreement to curtail. Performance monitoring communications may be required only in the one day to one-week range because they are only needed for billing and crediting purposes.

Load service communication does not carry the fast time requirements that transmission related communication does because the load services are not protective ${ }^{2}$ in nature, but are related to voltage drop and frequency decay. Transmission system communication times are relaxed when the line voltage classes are reduced. In the future, grid stability assessment such as low frequency harmonics in voltage and frequency would probably be performed locally, and control signals would be provided locally. In the future, intelligent distributed control agents scattered throughout the grid may monitor and analyze local conditions, detect problems such as frequency oscillations, voltage sag, etc., and send control and dispatch signals to local loads and generators to maintain desired voltage and frequency levels.

The following is a discussion of services that may be provided by load management and the associated load and control response time requirements for the services. A complete table of ancillary service types (i.e., those that can and cannot be provided by load) is provided in Section 2.2.

\section{Reactive power supply}

Loads could supply reactive power to the distribution system if they were equipped with power electronics that were capable of changing the power factor of the power supplied to the load. In the near future, this may be a practical concept and the same power electronics could also provide short-term energy storage and support the voltage during distribution system transients. The large majority of

\footnotetext{
${ }^{2}$ They are not related to protective relays that open circuit breakers in the event of short circuits and which operate in cycles.
} 
reactive power supply equipment is located on distribution systems, not the grid, because it is of most value when it is supplied at the load. Reactive power supply is sometimes switched on by time clocks that switch the supply on when the feeder load is heavy, but automatic switching controls respond to voltage, causing the reactive power supply to come on when voltage deviates below a preset level. In the case of switching by the dispatcher, response is also just a few seconds.

It is true that excessive VAR supply can elevate voltage, and an overvoltage sustained for just a few minutes can result in equipment damage, but if the control were based on sensed voltage, this would not be a problem. In this case, the VAR support would not need to be dispatched at all. In conventional distribution systems, capacitance is often switched using $900 \mathrm{MHz}$ commercial paging and distribution line carrier, VHF private paging and VHF radio, or using time clocks that are set to switch on the capacitance during peak load periods. In loads equipped with power electronics, it is likely that due to the sophistication of control already provided by the power electronics, that local control based on sensed voltage would be the obvious and least cost approach.

\section{Regulation}

Our discussion of regulation is divided into three parts: voltage, generation and frequency. In all cases, "regulation" refers to the rapid control of real or reactive power in order to maintain power system stability and quality of customer service.

Voltage Regulation - This service is the dynamic control of voltage through control of reactive power. It differs from Reactive Power Supply, which is the "bulk" provision of reactive power and responds more slowly. Voltage regulation is frequently provided by generators, static capacitors, and/or static Var compensators [2]. Voltage regulation, except when provided by loads equipped with power electronic interfaces to supply reactive power as discussed above, is probably not going to be provided by loads.

Loads may supply this service in unusual circumstances, such as in microgrids or large loads that have a major impact on the system. Loads equipped with a power electronics interface would supply this service with speeds of 2 to 3 minutes except in areas with rapidly fluctuating large loads. Regulation may be performed with a sensor with feedback to the voltage regulator with a simple voltage schedule that provides the specified voltage vs. time for the node.

Energy Imbalance - Energy Imbalance or Generation control is done to keep the net generation and load balance within an acceptable error (i.e., area control error). Response time to system events such as loss of a line, outages, or unusually high customer load is generally considered to be in the range of minutes. The Automatic Generation Control systems at most utility control centers send raise and lower pulses to individual generators as frequently as every two to four seconds, however, generators do not follow such short term load fluctuations. Generation typically follows load at one to two minute intervals. Loads whose profiles can be correlated may be useful in supplying this service. Recent research has shown that some large industrial loads may be controlled in such a way that their regulation burden is considerably reduced [3].

There is a growing potential that loads may play a significant role in Energy Imbalance. Highly varying industrial loads, such as arc furnaces and steel mills, may be correlated with each other. These loads are non-linear systems, and the principle of super-position cannot be applied. Neural network models are 
being prepared to represent multiple arc furnaces in a compound coherence analysis. Control strategies will then be developed to minimize the customer cost and the regulation burden to the utility [4]. This type of control system will be highly sophisticated and will require real time communication such as VHF radio or some other secure, real time system.

Other than through the above methods, it is unlikely that load will supply regulation, unless there are loads that are so unrestrained that they could be controlled to ramp up and down at a rate of perhaps 5\% per minute. At this time, the authors are not aware of loads that could do this.

Frequency Response - Generators typically are equipped with throttles so that a 5\% change in frequency will result in a $100 \%$ change in power output. Incremental changes in power output are achieved in less than 5 seconds. Provision of this service would be a new concept for loads, and could only be accomplished when loads are equipped with frequency sensors and could ramp back when they sense a frequency decay. This service goes beyond the inherent characteristic of motor loads to reduce consumption as frequency drops.

In the future, when large numbers of loads are aggregated, and their combined contribution in a particular geographic location starts to approach several hundred megawatts, power electronics may permit the loads to be modulated to control frequency oscillations. However, the communication system to the loads will not need to be fast because the control authority for this service must be local. There would not be enough time to sense the oscillation and then dispatch a signal from a central control authority. The local agent would sense the oscillation and control the load in a manner to dampen the oscillation. The loads would also have to be of a type that could provide this modulation. Pumping systems powered by adjustable speed drives are again one possibility. Conventional pumping systems provided a form of regulation because induction motors increased slip at lower voltages and the load decreased with roughly the cube of the speed change. At present, adjustable speed drives are working against inherent regulation because they hold the speed constant. This is a problem that must be addressed as more and more loads are equipped with adjustable speed drives.

The ramp rate for frequency response is typically very fast. Incremental changes are to be completed in 5 seconds or less. Again, it is unlikely that load will be providing this service in the near future.

\section{Spinning reserve}

This service has traditionally been the provision of generating capacity that is synchronized to the grid, that begins to respond or ramp up immediately, that is fully available within ten minutes, and that responds to frequency deviations or a signal to supply. It is used to correct for generation/load imbalances caused by generation or transmission outages. Ten minutes is a maximum time for the generation ramp up to be completed.

This is one service where the communication to dispatch will need to be rapid, on the order of 5 seconds to one minute. The central controller will probably directly dispatch the curtailment circuitry (i.e., the communications signal). If a large number of loads were aggregated, a pager or other radio signal could

\footnotetext{
${ }^{3}$ NERC recently relaxed this requirement to 15 minutes for control areas. The control area operator generally reserves 5 minutes for his own response. The resources themselves are still typically required to respond within 10 minutes.
} 
be used to provide the dispatch communication to all of them. Rapid communication may not be required, however, to verify that the load had curtailed. The circuitry will be periodically tested and verified to meet time and load shed magnitude requirements. Normal 15 minute interval metering will probably be adequate to verify the individual curtailments. The interval meter may, or may not communicate back to the central dispatcher. If the capability to curtail is periodically verified and shown to be reliable, the meter may only be needed for confirmation of curtailment and billing purposes.

This is a relatively high priced service, and in special cases where load has "built in" storage capacity of approximately twenty minutes to two hours, and can be automatically controlled, this service may be provided by loads. This service is typically provided for only a short time. There is a real possibility in the water pumping industry. This is discussed further in Section 2.2 (see notes to Table 2-1).

\section{Supplemental reserve}

This service is the provision of generating capacity to correct for generation/load imbalances caused by generation and transmission outages and that is fully available within ten minutes, but not required to begin responding immediately as spinning reserve is. The system operator takes some of the ten minutes to recognize the contingency and to call for response.

For this service, communication times of 5 to 7 minutes should be fast enough to direct loads to curtail. The CAISO year 2000 program required a one-minute scan rate from the Aggregated Load Meter Data Server (ALMDS) to the ISO for Replacement Reserve, and each meter behind the ALMDS was to be polled within 5 minutes. Non Spinning Reserve was required to have a four second scan rate from the ALMDS to the ISO EMS. The four-second time frame was considered necessary to ensure that operating reserve was managed in real time and to accommodate operator decisions. This four-second requirement was a key technical barrier for the CASIO Participation Load Program, and for 2001 it has been changed to 15 seconds (see Section 3.2.1).

The central controller will probably directly dispatch Curtailment circuitry. Again, rapid communication may not be required to verify that the load had curtailed. The circuitry will be periodically tested and verified to meet time and load shed magnitude requirements. Normal 15 minute interval metering will probably be adequate to verify the individual curtailments and for billing purposes.

Again, this is a candidate for loads with built in storage and is discussed further in Section 2.2.

\section{Backup supply}

The backup supply plan is a protocol that instructs the system operator how to proceed for each load's loss of primary supply. There is a 30-minute warning associated with this service therefore the dispatch communication would not have to be rapid. Four to five minutes should be adequate. It is possible that some loads may contract to provide backup supply for other loads.

\section{Real power loss replacement}

This is compensation for transmission system losses. It is unlikely that loads would provide this service. 


\section{Dynamic scheduling}

This is real time metering, telemetering, and computer software and hardware for electronically transferring some or all of a generator's output or a customer's load from one control area to another. It is unlikely that loads will provide this service.

\section{Network stability}

This is the use of fast response equipment to maintain a secure transmission system. There is a possibility that loads could supply this service, but the response has to be quite rapid, and in some cases it would not be a simple on-off type of response. The load would have to be modulated to dampen the frequency or voltage oscillation.

This service could only be provided by loads equipped with power electronic devices which could modulate the load impedance in response to the sensed voltage or frequency oscillation as described under the Frequency Response discussion above. Communication from the central control authority would be too slow. A local control agent would have to be capable of initiating and controlling the response. This local control philosophy will take a paradigm shift from convention central control logic, but will enable a much more reliable and efficient grid system.

\section{Load following}

This service is quite similar to regulation except that it occurs over a longer time frame to meet daily variations in load. The load following patterns of customers are highly correlated with each other, and the load changes are often predictable and have similar daily patterns because of weather dependence, etc. For this service, a communication time of 3 to 4 minutes should surely be adequate because it is typically dispatched in a one-hour interval. Likewise, the communication back to the central control would not need to be faster than 3 to 4 minutes.

Load following is measured in terms of real power capacity (i.e., MW) required over each hour. It is quite possible that load following could be provided by large controllable loads with some inherent storage, such as in pumping stations.

\section{System black start}

This service is the ability of a generating station to start up without assistance from the grid and then to energize the grid to help other units start after a blackout occurs. Some major loads, such as Air Force bases, do possess large-scale generation capability on the order of $10 \mathrm{MW}$ or more that could potentially be used as black start capability. Several megavars are needed just to energize a transmission line, and tens of megawatts are typically needed to restart large thermal generators.

This service introduces a number of special concerns for communication. System restoration practices differ from utility to utility, complicating the issue [5]. First of all, utilities are reluctant to use pagers or commercial telephone lines for communication during blackout or emergency conditions because phone lines are often overloaded during emergency conditions and pagers may be inoperable because of the blackout, or they may likewise be overloaded. Under black start conditions, dispatch commands are 
typically given and confirmed verbally over secure voice links. The normal SCADA system may or may not be available, though black start units are typically required to be connected to the SCADA system. This service will only be provided by loads with generators, and real time communication and control will be required because of the complex and unusual nature of this control evolution. In some cases, control areas have developed special black start control systems that have independent, battery-powered communication circuits and logic for a programmed restart. However, in most instances the control area operator manages black start in real time.

\subsection{Survey of Present Load Participation Methods and Markets}

This section looks at specific types of loads present in industry and methodically considers what potential each has for providing various types of ancillary services. The seven types of loads that will be considered are as follows:

Loads equipped with power electronics - The revolution in power electronics technology has resulted in the development of power quality correction devices that will not only improve the quality of power flowing downstream from the device, but will also improve the quality of the power drawn by the device from its upstream source. These devices can control the phase angle of the current so that the load can have a lagging power factor, like an inductor, or a leading power factor, like a capacitor. These devices are called "active" devices because they actively control the current flow through the device using transistor switches. They also employ a direct current bus, which makes short-term energy storage feasible.

Large industrial loads with imbalance correlation scheme ${ }^{-}$Large loads, such as steel mills with electric arc furnaces, can create power quality problems in the grid due to the sheer magnitude of their power demand. The adverse effects of Highly Varying Industrial Loads (HVLs) must be addressed especially in the area of load imbalance.

Utility pumping stations - Roughly $2 \%$ of the electrical energy used in the U.S. is used in Municipal Water Works. The most significant component of this Municipal Water Works energy is the pumping energy, which comprises an estimated $65 \%$ to $80 \%$ of the total [6]. There is significant energy storage built into water works systems in the form of reservoirs, water tanks, water distribution lines, etc. The often-huge magnitude of this storage makes many water works operations capable of providing significant levels of load reduction (i.e., potentially recognized as spinning power reserve) lasting many hours. Automatic load shedding circuits for pump runback could be developed that would provide for these high levels of reserve. Pump run back (i.e., slowing or stopping the pump) would be required for $1 / 2$ hour to 4 hours. In practice, this would most likely be accomplished at a pumping station by using adjustable speed drives to reduce and regulate water flow for both load reduction and the control of frequency decay.

If $50 \%$ of the pumping load were available for rapid, short term run back (i.e., a reasonable estimation), this would result in a reserve capability of roughly $1 \%$ of the total electrical energy used in the U.S. Since spinning reserve accounts for roughly $4 \%$ of a utility's peak demand, there appears to be the potential that Municipal Water Works alone could conservatively provide a fourth of the nation's entire spinning

\footnotetext{
${ }^{4}$ Such as that which NIPSCO is developing - see Table 2-1, Note 3.
} 
reserve requirement [7]! In addition, the water works would be paid continuously for providing this service even though it may be rarely called on. This makes the economics much more attractive than being paid under a typical interruptible load contract. In addition, this would free up existing generation to be used for peaking service. Most importantly, the older, less efficient generation which is typically kept idling to provide spinning reserve could be kept shut down except when it is required for peaking, thus lowering carbon emissions.

Loads with generators - Industrial loads coupled with power generation capability represents a highly flexible entity that can potentially provide a number of ancillary services. Depending on the control systems, power electronics, and generation capacity, the services that may be provided include voltage regulation, load balance, frequency-responsive spinning reserve, energy imbalance, system black start, and others.

National chains of several thousands stores - National chain stores account for a surprisingly large amount of load. One national retailer, with over 3,400 stores, has central control over temperature and lighting in all of their locations from their headquarters. Their newest stores have a load of $750 \mathrm{~kW}$ to $1 \mathrm{MW}$. They have a tremendous commitment to community involvement; they are always responsive to requests to curtail load due to local emergency conditions, and comply with utility requests for load reduction whenever there are shortages or other complications. In the last year, however, they have had over 36 requests to contract in load control programs, but they were only able to participate in one because of a number of constraints discussed below, which are probably typical of retail businesses.

Their best business hours roughly parallel electrical peak load hours. Customers start to come in over the lunch hour, and then business is usually brisk in mid and late afternoon. They have to keep the store comfortable and cool during these hours. They can never run back the refrigeration. Usually, their only option to reduce load is to dim some lighting. The maximum that can usually be shed is about $100 \mathrm{~kW}$. Many of the load control programs provide only one-hour notice, which is a problem when you have 3,400 stores. Many of the programs require a certain minimum load (i.e., larger that $100 \mathrm{~kW}$ ), and are based on a load profile instead of actual loading and do not consider actual real time weather. Other programs require installation of expensive meters that monitor the demand and time profile. The one program the above retailer contracted with required no new meter, and provides market-based rates using a website. They have the option of bidding or not, and they retain control.

Load aggregator - Load aggregators contract with a group of loads to supply a curtailment service. One such aggregator is, Apogee, who performs a valuable service by building Internet-based auction sites where customers are alerted to the day-ahead price and then post their willingness to participate at a price [8]. These demand reductions are accepted or rejected, then aggregated, and essentially act as a supply alternative. The economic benefits to the customer show up as credits on their future electric bill. Presently, Bonneville Power Administration has aggregated $300 \mathrm{MW}$ of load from customers who are participating in this program. This is discussed further in Section 4.3.

Individual large loads - A large load by itself typically lacks much of the versatility that exists in the above load types. However, in cases where operations and costs are not adversely impacted (i.e., beyond the bounds set by the industry), a potential exists for load reduction/supplemental reserve. 
Table 2-1 provides potential services that could be provided from loads and types of loads that may or may not be suited to provide this service. The table is based on the time requirement for the service and the estimated likelihood that the load type could indeed provide that service. Many of the services could not be provided unless there is a power electronics interface installed that provides the needed load control, reactive power output, voltage regulation, or other specific requirement. The most unique interface requirements are covered further in the notes immediately following the table.

\subsection{Application to SCE Load Management Programs}

This section provides a detailed example of how a large utility's current load management programs and system components (e.g., computer, communications, metering) can meet diverse requirements for facilitating a number of ancillary services. The example is taken from Southern California Edison's (SCE's) direct load control (DLC) programs.

Figure 2-1 illustrates the major functional elements of SCE's DLC programs. This section discusses the requirements for the load control receiver (LCR), data communications, the master computer, and the metering system.

\section{Regulation}

Load Control Receiver (LCR) overall technical requirements - The critical requirement of the LCR is its ability to respond to a control command within a time frame that would allow its impact (i.e., demand reduction) to be realized at the system level soon enough to provide the necessary load shift. Since the time frame "order of magnitude" is specified in minutes (rather that seconds or fractions of seconds), the only requirement of the LCR is to be able to respond with adequate speed. The LCRs are microprocessor controlled and have no internal time delay. In summary, the LCRs themselves can easily provide this kind of load balancing/regulation to the electric grid. The ability to get the message to the receiver on time is an additional requirement that will be discussed next.

Data Communications overall technical requirements - For traditional Direct Load Control (DLC) systems, the data communications capability of the load control system is the key limiting factor in its ability to supply reliable "Regulation" type ancillary services. ${ }^{\text {This fact is based on the typical }}$ performance of a dedicated communication infrastructure - one that is owned and operated by the utility and one that provides dedicated access. However, it is important to consider that in many instances around the country, the communications system (or more accurately the frequency) must be shared with other utilities. This "sharing" of the communications system inherently makes the communications system unavailable for critical "time specific" transmission of the control messages. Other systems around the country also share the communications medium with paging system providers raising the same issues. Even in an ideal situation where an owned and dedicated system exists, the communications network combined with the receiver response makes these types of direct load-control systems

\footnotetext{
${ }^{5}$ Obviously, another key factor is the ability of a load to rapidly move up and then down in a seemingly random fashion. Only very special loads will be able to provide this service and even fewer will find it economically attractive to do so.
} 
Table 2-1 Possibilities for End Use Methods and Technologies for Providing System Reliability Resources

\section{Ancillary Service Type}

\begin{tabular}{|c|c|c|c|c|c|c|c|c|c|c|c|c|c|}
\hline Load Type & $\begin{array}{l}\text { System } \\
\text { Control }\end{array}$ & $\begin{array}{l}\text { Reactive } \\
\text { Power } \\
\text { Supply }\end{array}$ & $\begin{array}{c}\text { Voltage } \\
\text { Regulation }\end{array}$ & $\begin{array}{c}\text { Regulation } \\
\text { Generation/Load } \\
\text { Balance }\end{array}$ & $\begin{array}{c}\text { Frequency } \\
\text { Responsive } \\
\text { Spinning } \\
\text { Reserve }\end{array}$ & $\begin{array}{l}\text { Supplemen } \\
\text { tal Reserve }\end{array}$ & $\begin{array}{l}\text { Backup } \\
\text { Supply } \\
\text { Plan }\end{array}$ & $\begin{array}{l}\text { Real Power } \\
\text { Loss } \\
\text { Replacement }\end{array}$ & $\begin{array}{c}\text { Energy } \\
\text { Imbalance }\end{array}$ & $\begin{array}{c}\text { Dynamic } \\
\text { Scheduling }\end{array}$ & $\begin{array}{l}\text { Network } \\
\text { Stability }\end{array}$ & $\begin{array}{c}\text { Load } \\
\text { Following }\end{array}$ & $\begin{array}{c}\text { System } \\
\text { Black } \\
\text { Start }\end{array}$ \\
\hline $\begin{array}{l}\text { Any load } \\
\text { equipped } \\
\text { with power } \\
\text { electronics }\end{array}$ & No & Yes & Possibly & Possibly & No & No & No & No & No & No & $\begin{array}{l}\text { Possibly - } \\
\text { See } \\
\text { Note } 1\end{array}$ & No & No \\
\hline $\begin{array}{l}\text { Possible } \\
\text { combined } \\
\text { steel mills } \\
\text { or other } \\
\text { large } \\
\text { industrial } \\
\text { loads with } \\
\text { imbalance } \\
\text { correlater } \\
\text { scheme }\end{array}$ & No & No & No & $\begin{array}{l}\text { NIPSCO } \\
\text { Program }- \text { See } \\
\text { Note } 2\end{array}$ & No & No & No & No & No & No & No & No & No \\
\hline $\begin{array}{l}\text { Utility } \\
\text { pumping } \\
\text { stations }\end{array}$ & No & No & No & Possibly & $\begin{array}{l}\text { Excellent- } \\
\text { See pumping } \\
\text { station } \\
\text { discussion }\end{array}$ & Excellent & Possibly & No & Possibly & No & No & Possibly & No \\
\hline $\begin{array}{l}\text { Loads with } \\
\text { generators }\end{array}$ & No & Yes & Possibly & Possibly & Possibly & Possibly & Yes & Possibly & Possibly & No & Possibly & Possibly & Possibly \\
\hline $\begin{array}{l}\text { National } \\
\text { chain of } \\
\text { several } \\
\text { thousand } \\
\text { stores at } \\
\text { 1MW each } \\
\text { e.g. } \\
\text { (Walmart) }\end{array}$ & No & No & No & Possibly & Possibly & $\begin{array}{l}\text { Yes - but } \\
\text { limited to } \\
\text { fairly small } \\
\text { percentage } \\
\text { of load }\end{array}$ & No & No & No & No & No & No & No \\
\hline $\begin{array}{l}\text { Load } \\
\text { Aggregator }\end{array}$ & No & No & No & Possibly & Possibly & Yes & Possibly & No & No & No & No & No & No \\
\hline $\begin{array}{l}\text { Individual } \\
\text { Large } \\
\text { Load }\end{array}$ & No & No & No & No & No & Possibly & Yes & No & No & No & No & No & No \\
\hline
\end{tabular}


It is also possible that "smart" power electronic devices could sense developing network problems such as frequency oscillations and modulate the load to dampen these oscillations, thus providing a network stability service.

\section{Table 2-1, Note 2}

The concept of loads supplying the Energy Imbalance service is truly revolutionary. Large loads, such as steel mills with electric arc furnaces, are notorious for being among the worst players in creating the need for energy imbalance correction. A study is now being performed by the Northern Indiana Public Service Co., Purdue University and the Colorado School of Mines under subcontract to the Oak Ridge National Laboratory for the DOE to analyze data from highly varying loads such as steel mills with electric arc furnaces to calculate their impact on Energy Imbalance. A model will be developed which will be used to study multiple industrial loads, coherence analysis and potential coupling effects. The model will provide direction for the control of the startup of arc furnaces as a means of reducing the influence of HVLs.

The arc furnaces are non-linear systems greatly complicating the modeling effort. A key feature of the model will be a flexible control strategy that will allow prediction and decision capability on when to release products into electrical demand intensive processes. The above study will identify how a scheme to optimize the benefits can be implemented in an operating control area, and State and Federal regulatory arena [4].

In the long term, HVLs may be able to utilize the control strategy to work together to reduce imbalance, minimize Area Control Error (ACE) and to provide a service for which they actually earn revenue. 


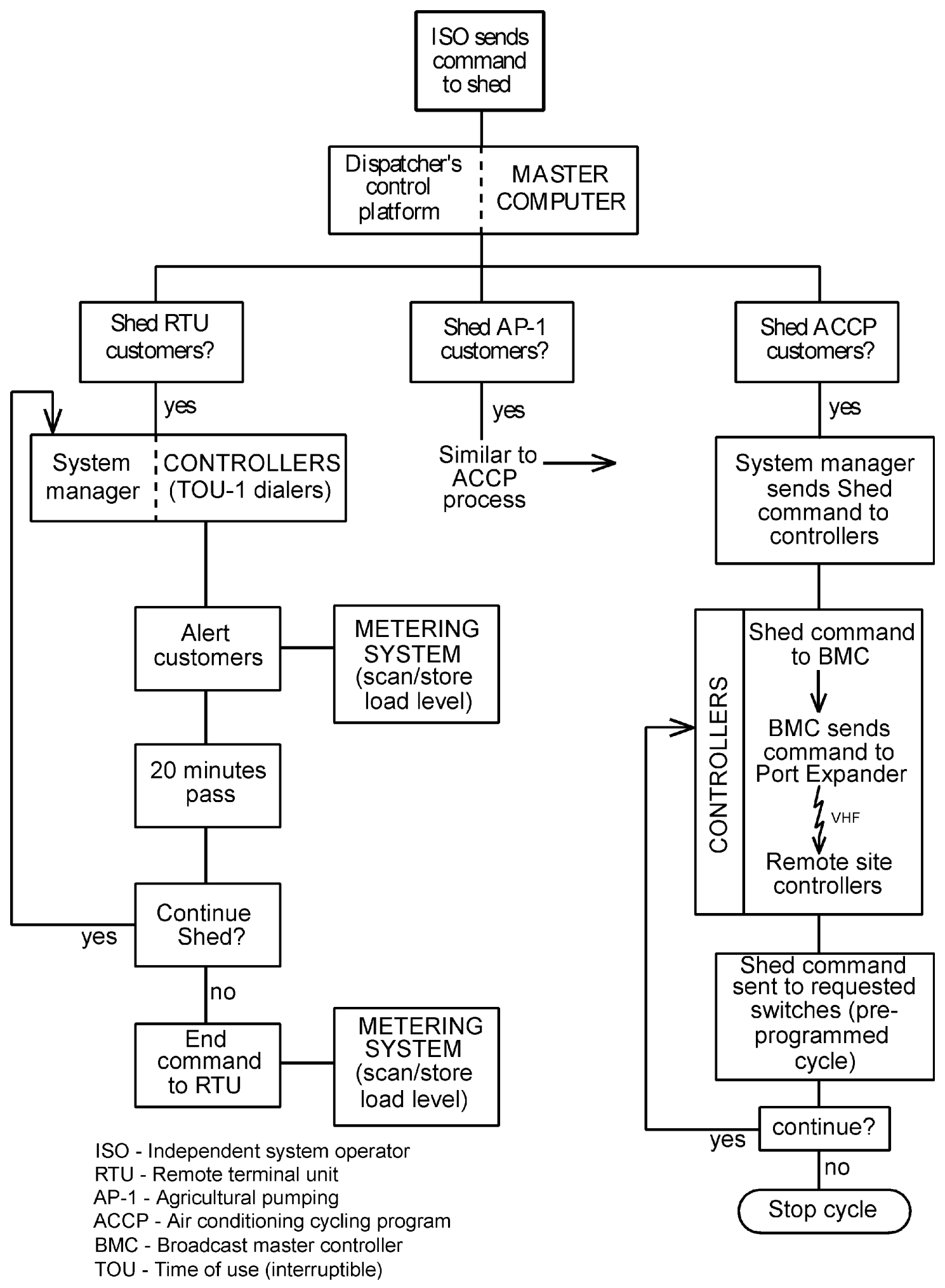

Fig. 2-1 Simplified diagram of SCE's direct load system 
unacceptable for Regulation applications. The typical response time for a DLC system in a dedicated environment is approximately 10 seconds. This means that from the time the system is "commanded" to shed load to the time the load is actually shed is about 10 seconds. The SCADA system must then detect the load shed and feed that information back to the AGC system. It is assumed here that the AGC system requires a more instantaneous response in order to maintain ACE.

Another consideration is that the DLC system must control loads (especially diversified loads such as Air Conditioners) in such a way that their loads do not loose their natural diversity [critical where duty cycle control (i.e. 15 minutes off and 15 minutes on) is being implemented]. This issue implies that the loads are not merely turned off but must be continuously cycled on an appropriate time base (e.g., 30 minutes). Another complexity occurs as the DLC system transitions from apparent load reduction, the effect of the first load shed command which is basically the average diversified demand of the appliance being controlled, to a more sustainable continuous average load reduction value, integrated over an hour. The sustainable load reduction is considerably less than the apparent load reduction observed early in the load shed process. In summary, as the controlled appliances are cycled and become "in synch" with control process, the only sustainable load reduction is a result in the lowering of the natural duty cycle of the appliance. This actual load reduction is significantly less than the average diversified demand of the appliance.

Master Computer overall technical requirements - The Master Computer technical requirements are relatively simple from a control perspective. The computer should support a concept known as "Distributed Intelligence" where the LCR determines on its own when to start and stop control thus maintaining appliance diversity. As long as the end control device (i.e., LCR) has this capability, the complexity of the control schemes that must be written into the Master Control Computer can be kept relatively simple. There are no inherent limitations to the Master Control Computer that inhibit the system's ability to provide this ancillary service.

Metering Systems overall technical requirements - For a traditional Direct Load Control system, the metering requirements at the individual customer level do not change. However, if the utility needs to understand what is actually happening at each individual customer (not the case for conventional systems) then the meter would have to be "automated" so that interval (e.g., 5, 10, 15 minute) consumption data could be retrieved and analyzed to determine the actual performance of each load control command and event.

\section{Load following}

LCR overall technical requirements - The critical requirement of the LCR for load following is the same as described above for regulation.

Data Communications overall technical requirements - In contrast to the Regulation ancillary service described earlier, the load following service requires a significantly less stringent system response time. Since this ancillary service assumes that the basic response time frame is in the order of 10 minutes, and especially since the load following patterns of many loads are predictable, DLC systems are ideally suited to provide this service. The fact that DLC systems are controlling loads on a duty-cycle basis actually becomes an advantage in this application. The reason for this is that the load reduction or increase can be "dispatched" in relatively small increments by merely adjusting the current duty cycle of the appliances 
being controlled. For example, these adjustments may be in the order of 1 minute per half hour. The response time of these changes may still be based on a 30-minute time base, but the load response begins to occur almost immediately (at least in the context of the current time frame). Of course, specified control strategies can be written to support a higher load change per minute requirement. This change in response rate adds complexity to the load control strategies and can expose the electric system to an undamped load swing situation if not properly designed. In summary, there are no inherent limitations within the data communications infrastructure that would prevent the DLC system from providing this ancillary service.

Master Computer overall technical requirements - The Master Control Computer must have the capability of handling the complex control strategies that are needed to provide the real time / on time response required by the system dispatcher. Considering the complexity of most known dispatch scenarios, the technical requirements of the Master Computer should not be an issue as far as providing this ancillary service, assuming that the software can respond to the functional requirements stated above.

Metering Systems overall technical requirements - The metering system requirements are not impacted except for the case where the utility/system implementer needs to validate or verify individual customer response. If this is a requirement, then meter automation is required that can support interval data in the order of 1,5,10 and 15 minutes. This granularity of the meter data will provide enough information to monitor individual system performance. This approach is in some ways preferable to a DLC system that monitors itself (the so called two-way DLC system). The reason for this is that by monitoring load impacts the utility/system implementer can capture all forms of system failure (e.g., tampering, improper appliance function, poor communications, hardware failure). Without the meter data, all the two-way version of the LCR can do is report on its own status - not the status of the entire installation.

\section{Voltage control}

LCR overall technical requirements - The use of conventional LCRs to control reactive power injection and absorption equipment is quite common throughout the United States. Some utilities have opted for a more sophisticated monitoring and control system for these applications (i.e., a version of traditional SCADA) primarily because they feel that they can justify the additional cost of ensuring that each device goes online on a real time basis. Most DLC systems today operate "one-way" therefore requiring that the successful deployment of the reactive power capacity be monitored via an existing SCADA system. This can normally be done at the substation by monitoring the VAR load on the substation or feeder.

Data Communications overall technical requirements - Even though this application is normally considered a real time function (dispatchable), the response to the dispatchers command by a DLC system can be more than adequate. This would likely be the case for privately-owned systems or those that use a shared network. For a dedicated DLC system the system response time is about 10 seconds, which system dispatchers will accept as adequate.

Master Computer overall technical requirements - The only burden for the Master Computer is its ability to support the load control strategies that must be written to provide this kind of functionality. Most DLC system controllers available today can support this capability. 
Metering Systems overall technical requirements - The only metering requirements for this application are associated with the SCADA system. Individual/end use meters with voltage and general power quality monitoring capability would be a great addition to the voltage control system's sophistication and would allow for the dispatchers to more accurately adjust system/distribution voltage. This end use metering for voltage control and power quality has not generally been considered a requirement for voltage regulation activities within the utility. The SCADA monitoring approach at the substation has generally been considered adequate.

\section{Spinning reserve}

LCR overall technical requirements - The LCR must be capable of responding to this requirement in a relatively short time frame as compared to the other ancillary services previously discussed. Since the LCR is microprocessor controlled there are no inherent time frame limitations within the LCR. The limitation is in the systems ability to sense the need for Spinning Reserve and then dispatch a load-shed command. It is the latter that dictates the performance of DLC systems for this service.

An alternate way to utilize the LCR for spinning reserve would be to equip the device with system frequency monitoring capability. The receiver could then be commanded and armed remotely by the system dispatcher to shed load at a particular frequency (e.g., $59.7 \mathrm{~Hz}$ ). By having the system decisionmaking capability "preloaded" into the LCR, the requirement to communicate with the LCR in real time, which is required for dispatchable spinning reserve functionality, is eliminated. The restoration of load would most likely be determined by the system dispatcher on a manual basis rather than having been preloaded into the receiver. This would eliminate a potentially unbalanced system scenario where too much shed or restore activity is occurring without dispatcher interface.

Data Communications overall technical requirements - As mentioned in the LCR section above the data communications system would basically have to support real time control capability - a capability that can not be supported by conventional DLC systems. In order to unburden the Data Communications system from this requirement, some additional intelligence must be implemented within the LCR.

Master Computer overall technical requirements - The Master Computer must have the ability to respond to a sensed under-frequency condition, select the required load shed strategy, and then implement the communications dispatching function all within less than 10 seconds. Most DLC systems in place today can barely support the maximum 10-second requirement. In general, the typical spinning reserve function allocated to DLC systems would be for the first load shed event. The DCL system would go first in hopes that its load reduction would be capable of stabilizing the electric grid before more-critical loads are shed by the traditional under-frequency control system that has been traditionally a part of system protection architecture. Therefore, it is critical that the DLC system responds very quickly, much less that the 10 seconds, in order to keep the more-critical loads from being shed. It basically depends on whether the DLC system can shed load fast enough to keep the system frequency above the trip points for the morecritical loads.

Metering Systems overall technical requirements - Metering in this application would be primarily used for monitoring the performace of the DLC system, either at the system level or at the end user location. This is the same as for other ancillary services. Obviously, if the customer or participant is being 
compensated for their contribution, then metered end-use contribution would allow for a more accurate compensation.

\section{Supplemental reserve}

LCR overall technical requirements - In comparison to the other ancillary services already discussed, supplemental reserve is the easiest for the DLC system to provide. The LCRs are inherently capable of providing the necessary control activity within the specified time frame (i.e., 10 minutes).

Data Communications overall technical requirements - As stated for the LCR, this technical requirement is the least stringent for the services discussed. The Data Communications capability of all current DLC systems, dedicated or shared, can easily provide the necessary load reduction within the specified 10minute time frame.

Master Computer overall technical requirements - The Master Computer simply needs to contain the specific control strategies that are appropriate for this application. This should not be an issue for most DLC systems.

Metering Systems overall technical requirements - As with all of the ancillary services discussed, the ability to monitor each customer's response to the control request would greatly help in providing fair and equitable compensation for their individual contribution to system load requirements.

\section{Backup supply}

The overall technical requirements for the LCR, data communications, master computer, and metering systems are similar to those described earlier for Supplemental Reserve.

\section{Dynamic scheduling}

The overall technical requirements for the LCR, data communications, master computer, and metering systems depend on the operational time requirements, etc.

System black start

SCE does not consider this ancillary service applicable to the discussion on load management.

\subsection{Summary of Findings}

Some key findings relating to ancillary services are as follows:

1. Many controllable customer loads appear suited to potentially provide some, but not all, ancillary services, notably system reserves such as spinning, non-spinning, and replacement reserve.

2. Some, such as water pumping by municipal or other utilities, potentially represent significant reliability resources; it is estimated that water pumping accounts for $2 \%$ of US electricity consumption. 
3. A key, yet currently under-developed, enabling technology that will allow distributed generation to provide certain ancillary services is the power electronic interface between the distributed generation and the grid.

4. Utility load management programs, such as direct load control, represent already well-organized efforts to deploy large blocks of customer loads as system reliability resources. 


\section{PROGRAM EXPERIENCE - PAST AND PRESENT}

In this section, our review of what is known about load control is continued by surveying a variety of programmatic approaches in which load is called on to act as a system reliability resource. The focus is on two fundamentally different programs triggered by (1) system conditions (e.g., forecast reserves fall below a threshold) and (2) a price signal (e.g., a real-time price), with an emphasis on programs triggered

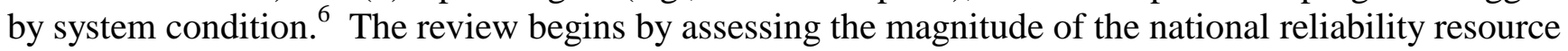
represented by existing utility load management programs. Then the review looks at the recent experience of several programs in emerging competitive markets: (a) the California ISO's Demand Relief and Participating Load programs; (b) Interruptible or load programs in California, which are operated in conjunction with California ISO's programs; and (c) the New England ISO's Load Management program. The final sub-section reviews the New Zealand experience with load management, which is a mature example of the integration of customer loads with electricity system reliability management.

\subsection{Review of U.S. Utility Load Management Programs}

The survey begins with an assessment of the total U.S. load management capability. DOE's Energy Information Administration (EIA) collects performance and cost information on two types of utility DSM programs: Load Management and Energy Efficiency. Load management programs are aimed specifically at reducing demand at critical times (such as summer or winter peak) and usually have only a minor effect on annual energy consumption. Energy efficiency programs are aimed at reducing annual energy use by promoting high efficiency equipment and building design. Though not designed solely for this purpose, energy efficiency programs also reduce electricity use at times of system peak demands peak demand depending on the end-uses and technologies targeted. This review considered only utility load management programs.

Historically, utilities have relied on two primary program types for load management: Direct Load Control and Interruptible Rate programs. In direct load control programs, the utility manages the operation of selected end-use appliances to achieve system load relief. The majority of these programs control residential and commercial air conditioning and water heating, and to a lesser extent residential pool and agricultural pumps. In interruptible load programs, the utility notifies the participating customer of the need for load curtailment and relies on the customer to determine and implement load reductions on their premise to achieve the firm service level specified in their contract with the utility. Some customers rely on back-up generation for this purpose (rather than curtail energy use). ${ }^{\text {th }}$

These utility load management programs constitute a large installed base of controllable loads that should be considered system reliability resources. The underlying communication, control, and metering technologies, as well as potentially the program designs and operational procedures, themselves, represent important, yet currently un-appraised (and potentially undervalued), assets for future competitive markets. In the short run, modified and improved operation of these programs may be the most effective form of

\footnotetext{
${ }^{6}$ See Hirst and Kirby (2001) for more extensive review of dynamic pricing programs and related issues.

${ }^{7}$ EIA stopped collecting information separately on direct load control and interruptible load programs after 1996; hence, our findings, which are based on data collected in 1998, do not distinguish between these two load management program types.
} 
demand-side response available to the electricity system today. Existing assets must be carefully scrutinized in light of recent technological advances and incremental investments considered.

EIA's annual information on utility demand-side management programs [9] collected in 1998 was analyzed to prepare aggregate statistics on load management capability (MW installed by utility type, region, and customer class) and 1998 performance (actual MW, and program costs).

The EIA data summary presented in this section provides information on the over 1,400 utility load management programs that were operated in $1998 .^{\text {D }}$ Program performance is reported in two ways reflecting the reliability-related purposes served by the programs: 1) installed capability of all load management programs; and 2) amount of capability actually interrupted or utilized in 1998.

Table 3-1 provides load management capability and utilization for the U.S. utility load management by utility type. Total installed capability of U.S. load management programs is $27.8 \mathrm{GW}$ (actual utilization in 1998 was 49\%). Ownership is primarily private (60\%) followed by Coops (18\%). Federal ownership is large, consisting solely of TVA (14\%). Table 3-2 provides the same information by customer class. Composition by customer class is primarily industrial (49\%), followed by residential (27\%), then commercial $(22 \%)$.

Table 3-3 (i.e., EIA data by region) shows that SERC contains largest regional load management assets (32\%), followed by WSCC (16\%) and MAPP (14\%). Remaining regions each have less than 10\% of national installed capacity.

Table 3-4 reports on the size of the largest utility load management programs. The largest five utility load management programs are owned by TVA (3900 MW), SCE (2284 MW), Duke (1236 MW), Alabama Power (1055 MW), and Florida Power and Light (1053 MW). The next largest program is less than 900 MW.

Table 3-1. U.S. Utility Load Management by Utility Type

\begin{tabular}{|c|c|c|c|c|c|}
\hline Utility Type & $\begin{array}{l}\text { Capability } \\
\text { (MW) }\end{array}$ & $\begin{array}{l}\text { Utilization } \\
\text { (MW) }\end{array}$ & $\begin{array}{l}\text { Utilization/ } \\
\text { Capability }\end{array}$ & $\begin{array}{l}\text { Capability } \\
\text { (\% of total) }\end{array}$ & $\begin{array}{l}\text { Utilization } \\
\text { (\% of total) }\end{array}$ \\
\hline Private & 16810 & 7920 & $47.1 \%$ & $60 \%$ & $58 \%$ \\
\hline Municipal & 1087 & 704 & $64.8 \%$ & $4 \%$ & $5 \%$ \\
\hline Coop & 4892 & 2405 & $49.2 \%$ & $18 \%$ & $18 \%$ \\
\hline Federal & 3900 & 1800 & $46.2 \%$ & $14 \%$ & $13 \%$ \\
\hline State & 22 & 20 & $90.9 \%$ & $0 \%$ & $0 \%$ \\
\hline Unknown & 1128 & 791 & $70.1 \%$ & $4 \%$ & $6 \%$ \\
\hline Total: & 27839 & 13640 & $49.0 \%$ & & \\
\hline
\end{tabular}

\footnotetext{
${ }^{8}$ EIA does not require reporting on DSM program by utilities with annual sales of less than 150 GWh. With the exception of consistency checks, EIA conducts limited independent review of the data submitted by the utilities on their DSM program activities.

${ }^{9}$ In any given year, a utility may or may not interrupt (i.e., utilize) its entire load management capability.
} 
Table 3-2. U.S. Utility Load Management by Customer Class

\begin{tabular}{lrrrrc}
\hline $\begin{array}{l}\text { Customer } \\
\text { Class }\end{array}$ & $\begin{array}{l}\text { Capability } \\
\text { (MW) }\end{array}$ & $\begin{array}{l}\text { Utilization } \\
\text { (MW) }\end{array}$ & $\begin{array}{l}\text { Utilization/ } \\
\text { Capability }\end{array}$ & $\begin{array}{l}\text { Capability } \\
\text { (\% of total) }\end{array}$ & $\begin{array}{l}\text { Utilization } \\
\text { (\% of total) }\end{array}$ \\
\hline Residential & 7583 & 3888 & $51.3 \%$ & $27 \%$ & $29 \%$ \\
Commercial & 6076 & 3349 & $55.1 \%$ & $22 \%$ & $25 \%$ \\
Industrial & 13708 & 6123 & $44.7 \%$ & $49 \%$ & $45 \%$ \\
Other & 473 & 281 & $59.4 \%$ & $2 \%$ & $2 \%$ \\
Total: & 27840 & 13641 & $49.0 \%$ & & \\
\hline
\end{tabular}

Table 3-3. U.S. Utility Load Management by Region

\begin{tabular}{|c|c|c|c|c|c|}
\hline$\overline{\text { Region }}$ & $\begin{array}{l}\text { Capability } \\
(\mathrm{MW})\end{array}$ & $\begin{array}{l}\text { Utilization } \\
(\mathrm{MW})\end{array}$ & $\begin{array}{l}\text { Utilization/ } \\
\text { Capability }\end{array}$ & $\begin{array}{l}\text { Capability } \\
\text { (\% of total) }\end{array}$ & $\begin{array}{l}\text { Utilization } \\
\text { (\% of total) }\end{array}$ \\
\hline$\overline{\mathrm{ECAR}}$ & 1542 & 1137 & $73.7 \%$ & $6 \%$ & $8 \%$ \\
\hline ERCOT & 272 & 92 & $33.8 \%$ & $1 \%$ & $1 \%$ \\
\hline FRCC & 2344 & 1874 & $79.9 \%$ & $8 \%$ & $14 \%$ \\
\hline МААС & 2331 & 462 & $19.8 \%$ & $8 \%$ & $3 \%$ \\
\hline MAIN & 2255 & 1517 & $67.3 \%$ & $8 \%$ & $11 \%$ \\
\hline МАРP & 3617 & 2125 & $58.8 \%$ & $13 \%$ & $16 \%$ \\
\hline NPCC & 384 & 293 & $76.3 \%$ & $1 \%$ & $2 \%$ \\
\hline SERC & 8873 & 3205 & $36.1 \%$ & $32 \%$ & $23 \%$ \\
\hline SPP & 1651 & 658 & $39.9 \%$ & $6 \%$ & $5 \%$ \\
\hline WSCC & 4505 & 2244 & $49.8 \%$ & $16 \%$ & $16 \%$ \\
\hline ASCC & 11 & 4 & $36.4 \%$ & $0 \%$ & $0 \%$ \\
\hline HI & 54 & 28 & $51.9 \%$ & $0 \%$ & $0 \%$ \\
\hline Total: & 27839 & 13639 & & & \\
\hline
\end{tabular}

The Table 3-4 also indicates that several of these large programs are within, or adjacent to, the boundaries of existing ISOs (e.g., CAISO - SCE, PG\&E, and SMUD; PJM - BG\&E, PEPCO, and PSE\&G). In addition, several are in areas in which ISO/Transcos are forming (Comm Ed, NSP, Central Ill, WEPCO, IES, Ohio Power). The significance of this finding is that, as described in the next sub-sections of the report, ISOs are developing programs for loads to provide system reliability services. Hence, the value of these utility assets may change as these programs expand. 
Table 3-4. Largest Utility Load Management Programs (1998)

Firm

Capability Residential Commercial Industrial (MW)

\begin{tabular}{|c|c|c|c|c|}
\hline Tennessee Valley Authority & 3,900 & $0 \%$ & $0 \%$ & $100 \%$ \\
\hline Southern California Edison Co ${ }^{1}$ & 2,284 & $11 \%$ & $86 \%$ & $0 \%$ \\
\hline Duke Power Co & 1,236 & $41 \%$ & $6 \%$ & $52 \%$ \\
\hline Alabama Power Co & 1,055 & $3 \%$ & $1 \%$ & $96 \%$ \\
\hline Florida Power \& Light Co & 1,053 & $59 \%$ & $41 \%$ & $0 \%$ \\
\hline Commonwealth Edison $\mathrm{Co}^{2}$ & 848 & $5 \%$ & $95 \%$ & $0 \%$ \\
\hline Public Service Co of Colorado & 700 & $0 \%$ & $100 \%$ & $0 \%$ \\
\hline Florida Power Corp & 681 & $100 \%$ & $0 \%$ & $0 \%$ \\
\hline Northern States Power $\mathrm{Co}^{2}$ & 626 & $27 \%$ & $40 \%$ & $33 \%$ \\
\hline Nebraska Public Power District & 566 & $4 \%$ & $0 \%$ & $96 \%$ \\
\hline Pacific Gas \& Electric Co ${ }^{1}$ & 559 & $0 \%$ & $0 \%$ & $100 \%$ \\
\hline Arkansas Electric Coop Corp ${ }^{2}$ & 529 & $0 \%$ & $0 \%$ & $100 \%$ \\
\hline Baltimore Gas \& Electric Co ${ }^{1}$ & 516 & $55 \%$ & $45 \%$ & $0 \%$ \\
\hline Central Illinois Light $\mathrm{Co}^{3}$ & 510 & $0 \%$ & $0 \%$ & $100 \%$ \\
\hline Potomac Electric Power Co ${ }^{1}$ & 418 & $61 \%$ & $39 \%$ & $0 \%$ \\
\hline Mississippi Cnty Elec Coop Inc & 406 & $0 \%$ & $0 \%$ & $100 \%$ \\
\hline Wisconsin Electric Power Co ${ }^{2}$ & 391 & $14 \%$ & $0 \%$ & $86 \%$ \\
\hline IES Utilities Inc ${ }^{3}$ & 363 & $10 \%$ & $2 \%$ & $88 \%$ \\
\hline Ohio Power $\mathrm{Co}^{3}$ & 361 & $4 \%$ & $0 \%$ & $96 \%$ \\
\hline Public Service Electric\&Gas Co ${ }^{1}$ & 361 & $26 \%$ & $57 \%$ & $17 \%$ \\
\hline Sacramento Municipal Util Dist ${ }^{1}$ & 342 & $63 \%$ & $37 \%$ & $0 \%$ \\
\hline
\end{tabular}

1. In or adjacent to existing ISOs

2. In or adjacent to emerging ISOs/Transcos

3. These firms no longer operate as distinct entities; they are each now part of a larger utility

\subsection{California Summer 2000 Programs}

Utilities and ISOs around the country are currently engaged in nascent efforts to develop programs that attempt to tap customer load management activities explicitly as reliability resources [10]. Maturation of these programs will be accelerated by greater sharing of program experiences among current and other potential program sponsors and market participants. California's Summer 2000 load programs offer insight into a leading edge example of the potential role for customer loads in providing electricity system reliability resources in restructured electricity markets. Two new programs were created by the California ISO (or CAISO). In addition, CAISO also dispatched the load management programs of PG\&E and SCE.

\subsubsection{California ISO participating load and demand relief programs}

In preparation for anticipated capacity shortages in the summer of 2000, CAISO developed two pilot programs in which customers and load aggregators could provide loads directly to CAISO as reliability 
resources. ${ }^{10}$ The first program, called Ancillary Services Load Program (also referred to as the Participating Load Program), allowed customers to bid directly into CAISO-run markets for non-spin reserve, replacement reserve, and supplemental energy. The second program, called the Demand Relief (DR) Program, was akin to utility interruptible load programs. The DR program allowed customers to offer their loads to CAISO for dispatch during both Stage 1 and 2 emergencies.

\section{Participating load program}

All single or aggregated loads greater than $1 \mathrm{MW}$ were eligible in the program. Loads in utility distribution company interruptible programs were allowed if approved by CPUC. Targets for participation in the program were non-spin reserve, $400 \mathrm{MW}$; replacement reserve, $400 \mathrm{MW}$; and supplemental energy, $1000 \mathrm{MW}$. The duration of the program was from June 15 through October 15.

The payment structure is determined by the wholesale competitive markets for ancillary services (i.e., non-spin and replacement). Capacity payment is made if the supplier is successful in the day-ahead auction; energy payment is made if dispatched in real-time. Energy payment is also made for supplemental energy if dispatched in real-time.

Operationally, loads are bid into markets every hour by the Scheduling Coordinator (SC). Dispatch occurs through CAISO's automated dispatch system to the SC. Settlements are made through the SC.

A condition of participation is a signed Participating Load Agreement, which specifies compliance with CAISO's technical standards (e.g., telemetry and metering requirements).

No new loads participated in the Summer 2000 program. Program participants cited the high cost of equipment required to meet CAISO's telemetry requirements (4-second observability) as a primary obstacle to participation [11].

Changes have been made for the Summer 2001 program [12,13]. Telemetry requirements have been modified such that the requirements for supplemental energy are eliminated. Telemetry requirements for non-spin and replacement reserve have been relaxed from a 4-second scan rate to a 15-second scan rate.

\section{Demand relief program}

Single or aggregated loads greater than $1 \mathrm{MW}$ were eligible for the program. Loads in any other demand responsiveness program (e.g., utility distribution company interruptible load programs) were not allowed. The duration of the program was from June 15 through October 15. The payment structure for 2000 featured a capacity reservation payment paid on a monthly basis, subject to a tiered performance offset. Capacity reservation payments paid as bid by program participants. Energy was paid as dispatched at energy imbalance price.

Operationally, this program was activated at the end (i.e., in terms of reserves available) of a Stage 1 emergency (i.e., reserves below 7\%) following exhaustion of Balancing Energy and Ex-Post Pricing (BEEP) software stack. CAISO could call for up to 30 hours of interruption per month between hours of

\footnotetext{
${ }^{10} \mathrm{http}: / /$ www.caiso.com/clientserv/load/
} 
1200-2000 weekdays and participants have 30 minutes to respond. Performance was assessed by comparing loads during day of interruption to a 10-day rolling average. CPUC approved interval meters were required for participation in the program.

The goal was to obtain 1,000 MW of offers into the program. Sixty-seven responsive offers were received and evaluated, representing $269 \mathrm{MW}$ of load. Of these, 6 offers representing $180 \mathrm{MW}$ were accepted. The average capacity price was $\$ 36,000$ per MW-Month. Ultimately, only 4 participants, representing 55-67 MW of load, participated in the program. Some load bid for the program opted out due to the inability to install interval metering by the beginning of the program [14]. Other load dropped out due to the inability to use back-up generators as a result of air quality permitting issues.

The DR program was operated 20 times during the summer of 2000 (see Table 3-5). There were 11 Stage 1 and 17 Stage 2 emergencies called during the summer of 2000. See discussion of California utility interruptible load management programs (Section 3.2.2).

Demand reductions relative to contracted amounts are reported in Table 3-6. Performance relative to contracted demand reductions varied widely among participants; some participants performed consistently well. Performance was affected by equipment failures and, in some cases, by end-use customers opting not to perform. Performance was influenced by the number of successive days used, the length of curtailments, and the nature of the curtailment orders [14].

Table 3-5 California ISO Demand Relief Program Operation - Summer 2000

\begin{tabular}{llll}
\hline Month & Hours Available & Hours Used & Number of Events \\
\hline June & 15 & 15 & 3 \\
July & 30 & 16 & 4 \\
August & 30 & 30 & 8 \\
September & 30 & 24.5 & 5 \\
October & 15 & 0 & 0 \\
Source: Doudna, 2001 & &
\end{tabular}

Table 3-6 California ISO Demand Relief Program Performance - Summer 2000

\begin{tabular}{llll}
\hline June & July & August & September \\
\hline $44.3 \%$ Average & $66.0 \%$ Average & $66.4 \%$ Average & $55.4 \%$ Average \\
$99.7 \%$ Best & $100 \%$ Best & $100 \%$ Best & $99.5 \%$ Best \\
\hline
\end{tabular}

Source: Doudna, 2001

Stakeholders offered substantial input to CAISO on ways to improve the program for Summer 2001. Eligibility remains unchanged: Single or aggregated loads greater than 1 MW (i.e., no change from 2000). Loads in any other demand responsiveness program (e.g., utility distribution company interruptible programs) are not allowed. DR backup generation program participants must provide proof of applicable permits from local air quality management district. 
Program period will shift to June 1 - October 1. The 2000 program period was June 15 through October 15 however it was changed after the early June 2000 heat wave caught CAISO by surprise.

Target participation for 2001 is $1000 \mathrm{MW}$ through a request for bids (i.e., no change from 2000). Two separate programs are planned. One program is for demand relief through load curtailment, DR-Load and the other is for demand relief through the use of back-up generation (DR-BUG).

Payment Structure has changed to feature both: a) a capacity reservation payment paid on a monthly basis, subject to a linear (not tiered performance offset) of $\$ 20,000 / \mathrm{MW}$-month, and b) energy payments paid as delivered, also subject to a linear performance offset (not just energy imbalance price) of \$250/MWh.

Operationally, the DR program will now be activated only at the end (in terms of reserves available) of a Stage 2 emergency (reserves below 5\%), not at the end of Stage 1. The program will be activated following exhaustion of all utility interruptible loads and will represent the CAISO's last load action prior to a Stage 3 emergency (reserves below 1.5\%), which is the point at which UDC's are directed to initiate rolling blackouts. The DR-Load program will be activated prior to the DR-BUG program. DR-BUG will be operated when operating reserves are at $3 \%$ and forecast to reach $2 \%$ in 30 minutes.

Participation in the DR-Load program allows the CAISO to call for up to 32 (was 30) hours of interruption per month between hours of 1100-1900 (was 1200-2000) weekdays. Curtailments will last no more than 4 hours (there were no limits in 2000). No call will be made after 1700. CAISO will establish two, roughly equal size load blocks; each will be operated independent of the other; blocks may overlap or be sequence to follow the other. Participants have 35 (was 30) minutes to respond. Performance is assessed by comparing loads during day of interruption to a 10-day rolling average (no change from 2000).

Participation in the DR-BUG program allows the CAISO to call for operation of back-up generation up to 4 times per month, each lasting up to 3 hours, but no more than 7 times in 4 months, between 1100 and 1900 weekdays. Response is required within 15 minutes. Generation must be switched off within 30 minutes of CAISO order to terminate operation.

\subsubsection{California IOU summer 2000 interruptible load programs}

Because they are, in fact, activated by the CAISO, we also performed a preliminary review of Southern California Edison (SCE) and Pacific Gas and Electric (PG\&E) Interruptible Load programs to identify issues facing existing utility load management programs as they transition from operation in regulated utility settings to operation in restructured electricity markets $[15,16]$. Technical aspects of SCE's direct load control programs from the standpoint of future provision of ancillary services were reviewed earlier in Section 2.2.

Existing utility interruptible load programs already embody many characteristics that may be incorporated into future reliability-motivated load participation programs: (1) interruptions are triggered by a signal from the utility in response to system conditions; (2) customers have substantial discretion over the manner in which load is shed, in some cases including reliance on distributed generation (in contrast to direct load control programs that turn off designated pieces of end-use equipment); (3) customers at times 
have discretion over whether or not to interrupt at all; and (4) the utility already has procedures in place to verify interruption. The near-term technical potential for load relief is substantial. However, there are significant unresolved technical and institutional issues, including observability (telemetry) issues, and the scope of utilities' future retail activities (including operation of load management programs) in competitive markets.

As noted in Section 3.1, SCE and PG\&E operate two of the largest load management programs in the U.S. (i.e., $2284 \mathrm{MW}$ and $559 \mathrm{MW}$, respectively). Interruptible loads represent the largest element of these programs (i.e., about $1800 \mathrm{MW}$ for SCE and $500 \mathrm{MW}$ for PG\&E). These programs currently operate in a market setting that has seen significant change over the last few years starting with the creation of the CAISO.

Both programs are activated by the CAISO. CAISO is in constant communication with Transmission Operations (formerly the Energy Control Centers) of the three utility distribution companies (UDCs), PG\&E, SCE, and SDG\&E. CAISO will typically forecast a day ahead whether they expect the emergency energy procedure (EEP) to be in effect. As the day progresses, they will issue Alerts, Warnings and, if necessary, a Stage 1 Emergency (i.e., at operating reserves less than 7\%) and then a Stage 2 Emergency (i.e., at operating reserves less than 5\%). As part of a Stage 2 Emergency, and in accordance with the provisions of the nonfirm tariffs E-19 and E-20 (PG\&E) and I-6 (SCE), the ISO will direct the LDCs to schedule curtailments and request a specific load reduction amount from each LDC.

When the Transmission Operator at each LDC receives the curtailment request, they will proceed to implement it according to the specific procedures they have in place. Both SCE and PG\&E have loadblocking schemes that allow them to allocate curtailment requests evenly among all the participants [18].

\section{Southern California Edison}

The capability of SCE's interruptible program is $1800 \mathrm{MW}, 12$ consisting of customers on its I-6 tariff. The rate discount customers receive for participation is approximately $\$ 180$ million/year or $\$ 100,000 / \mathrm{MW}$-year (about a 15\% discount on a customer's annual electricity bill). Interruptions are permitted for up to 25 times for a maximum of 6 hours per interruption, or a total of 150 hours/year (\$667/MWh). The penalty for not reducing load below Firm Service Level is \$700/MWh.

SCE has 9 non-geographic load blocks of approximately $200 \mathrm{MW}$ each for a total of $1800 \mathrm{MW}$. SCE also has an AC control program of $230 \mathrm{MW}$ and an agricultural interruptible pumping program of $50 \mathrm{MW}$. SCE operates the residential air conditioning and small agricultural interruptible programs first, and then operate only enough I-6 customers to meet the CAISO's request.

SCE has remote terminal units (RTUs) installed in each I-6 customer premises. The SCE Transmission Operator activates the notification system to the load blocks next in order as needed to satisfy the CAISO

\footnotetext{
${ }^{11}$ The following two sub-sections are based the referenced memo by Heffner.

12 According to CPUC, SCE has about $2900 \mathrm{MW}$ of load on the I-6 tariff; however, it expects and plans on only about 1800 MW as being available for curtailment. If cost is based on total MW on I-6, the cost per MW drops to less than $\$ 70,000 / \mathrm{MW}$ year, as reported in CPUC (2000).
} 
load reduction request. Each customer RTU has its own unlisted, dedicated phone line, with a back up, dedicated, incoming-calls-only phone line.

The RTU has several functions: (1) instantaneous read-out of the customer's kW demand during both interruptions and normal operation; (2) visual and audio alarms that alert the nonfirm customer of an impending operation; (3) a relay that can be connected to one or more internal automatic load-shedding devices; (4) an acknowledgement button that communicates with SCE and silences the alarm; and (5) back-up batteries that ensure the unit will function even during an $\mathrm{AC}$ power outage.

If the customer does not acknowledge the alarm, an SCE representative will make a manual notification phone call via the back-up phone line. Once the customer receives the notification, they must curtail below their Firm Service Level within 30 minutes or face substantial penalties ( $\$ 700 / \mathrm{MWh})$. The RTU is the official time-stamped SCE nonfirm notification vehicle.

The notification that the curtailment period is over is done in exactly the same way. Sometimes the curtailment will be cancelled or shortened if system conditions do not turn out to be as adverse as the forecast.

\section{Pacific Gas and Electric}

PG\&E's interruptible load program contains about $500 \mathrm{MW}$ of curtailable load under tariff designations E-19 and E-20. Customers receive an annual rate discount of approximately $\$ 40$ million/year or $\$ 80,000 / \mathrm{MW}$-year. Up to 30 interruptions per year for a maximum of 6 hours per interruption, or a total of 100 hours/year $(\$ 800 / \mathrm{MWh})$ are permitted under the program.

PG\&E uses geographical load blocks that correspond to their Transmission Planning Areas (TPAs). This allows them important flexibility, as specified in the nonfirm tariffs, to curtail the customer in response to local transmission system emergencies as well as statewide electric emergencies. This has happened several times in different TPAs since 1998. Because the load blocks are geographical they are not of uniform size. SF Local and Humboldt Local are the smallest, with only 5 and $12 \mathrm{MW}$, respectively. The other areas, named for major transmission corridors such as ZP26 and NO Path 15, vary in size from 40 MW to over $100 \mathrm{MW}$.

PG\&E's notification system is less sophisticated than SCE's. CAISO notifies PG\&E's Electric Transmission Planning and Operations (ETPO) of a Stage 2 emergency and further specifies when and how much load reduction they require from PG\&E. If there is no need for transmission area specificity, PG\&E then apportions the load relief among the nonfirm groups to roughly even out the number of curtailments and number of curtailment half-hours. (Note that customers are sensitive to both the total number of curtailments and the total cumulative time of curtailment).

Once the order of dispatch is determined, the Demand Control Center activates the Nonfirm Notification System, which is basically a programmable automatic faxing system. A fax to a dedicated fax machine on a dedicated phone line at the customer's premise is the official time-stamped PG\&E nonfirm notification vehicle. The Tariffs and Marketing Departments at PG\&E HQ and the regional level are also notified which customers have been asked to curtail. They then activate their own parallel courtesy notification schemes, which can include e-mails, e-paging, and phone calls to key contacts. 
The notification that the curtailment period is over is done in the same way. Sometimes the curtailment will be cancelled or shortened if system conditions do not turn out to be as adverse as forecast.

\section{Recent interruptible program experience and regulatory issues}

California's investor-owned utilities (PG\&E, SCE, and SDG\&E) have operated interruptible load programs since the mid-1980's. Because California was in capacity surplus throughout most of the 1990's, the utilities' interruptible programs were seldom used until the Summer of 1998. The programs were called 5, 2, and 13 times in 1998, 1999, and 2000, respectively.

In October 2000, the CPUC issued an Order Instituting Rulemaking (OIR) on the operation of interruptible load programs [19]. The OIR was issued following the Summer of 2000 in which interruptible customers were called upon to interrupt loads 13 times and was a response to concerns that customers wished to opt out of the program following this experience. Among other things, the OIR proposed the temporary suspension of the tariff provisions that allowed customers to opt out.

In February 2001, the CPUC's Energy Division released a report on interruptible programs and rotating outages [19]. The report indicated that compliance during 2000 (i.e., percent of expected interruptions actually delivered) had been $96 \%$ for PG\&E and $62 \%$ for SCE. Non-compliance penalties for SCE's participants were estimated at $\$ 92$ million for 2000. For just the month of January, 2001, the report indicated that $\mathrm{PG} \& \mathrm{E}$ had already exhausted the allowed number of curtailments for its program and that SCE had only about $50 \%$ of its allowed curtailments left.

\section{Summary}

Some key findings of the present programs include:

1. PG\&E's and SCE's interruptible load program participants represent a potentially large reliability resource for California. Efforts to tap this resource last summer were initially successful but performance decreased over time.

2. Many customers not accustomed to the requirements for interruptions (because they had not been called for many years) indicated that they would like to drop out of the current programs.

3. The CPUC opened an investigation to re-examine the UDC's interruptible load programs and to contemplate changes in them toward increasing their contribution to system reliability, especially for Summer 2001. Among other things, the CPUC has denied customers the opportunity to leave the current interruptible programs while it conducted its investigation.

4. The CPUC's reexamination is complicated by the advent of new programs offered both by the UDCs and by CAISO, which "compete" for the same loads. Resolution of the future of these programs depends, on one's vision for the provision of retail energy services by UDCs and new market entrants, as well as one's vision for the role of CAISO in managing "retail" reliability programs. 


\subsection{ISO New England Load Management Program}

This sub-section presents ISO New England, Inc. or ISO-NE's activities in developing and implementing programs to use electrical load as a resource. ISO-NE in recent years has demonstrated a strong interest in pursuing load management initiatives. For instance, in 1999 ISO-NE filed a load response program for the summer that was initially designed by a working group of the Regional Markets Operations Committee. The plan administratively predetermined the price paid to customers signed up and actually interrupted and program costs (i.e., to pay for interruptions) were allocated 50\% to Electrical Load (i.e., supplier of electricity) and 50\% to market participants (i.e., members of NEPOOL) based upon their adjusted monthly peak. However, this early pilot program did not encourage the kind of strong participation that was hoped for; this section discusses current revisions to address this situation.

In pursuing the concept of using load as a resource, ISO-NE has worked within the Northeast Power Coordinating Council (NPCC) to generate new ideas and develop successful pilot programs. ISO-NE has also aggressively petitioned the FERC for emergency action that would rapidly put new programs in effect. Another, more-recent indication of how serious ISO-NE's program has become is demonstrated by a conference it sponsored in October 2000 on, Enhancing Load Response Opportunities in Competitive Markets. Other sponsors were signatories of the ISO Memorandum of Understanding and the Northeast Regulatory Memorandum of Understanding Working group.

ISO-NE has a goal of reducing their on-line commitment (i.e., operating reserve) and has established a target of 300 to $600 \mathrm{MW}$. This would reduce production cost by up to $\$ 30$ million per year and significantly reduce harmful air emissions [20]. It is estimated that $\mathrm{NO}_{\mathrm{x}}$ would be reduced by 280 tons, $\mathrm{SO}_{2}$ by 200 tons, and $\mathrm{CO}_{2}$ by 230,000 tons. In order to reach these goals, ISO-NE hopes to quantify and document their load reserve, which would then permit them to reduce their on-line commitment. ISO-NE is quite enthusiastic about this program since it would increase their reduction of on-line commitment from the current $15 \mathrm{MW}$ to at least $300 \mathrm{MW}$.

The basis and vehicle for the non-spin reserve program is the curtailable load program. The load response program is designed to increase ISO-NE's load reserve. The following sections describe programs in this area that demonstrate serious attempts by ISO-NE to create strong load response programs that are highly attractive to industrial Participants.

\subsubsection{Summer of 2000 load response program}

ISO-NE, in conjunction with the NEPOOL, developed a load response program for the summer of 2000. This program was designed to facilitate the contracting of several hundred megawatts of price-responsive load that would help to curtail demand during capacity deficiencies during the peak summer demand. The program was voluntary and was not intended to provide 10-minute response (i.e., spinning reserve).

In April of 2000, discussions were held on the early plan with participants and ISO-NE within the NEPOOL Markets Committee. There was early agreement on the premise that each qualifying customer would be paid for agreeing to interrupt its load pursuant to the terms of a contract entered into between the customer and the participant enrolling the customer. Beyond that, there were two draft proposals under consideration. The first used a predetermined price (i.e., strike price) at which participants would enroll customers and that price would serve as a floor for the Energy Clearing Price (ECP). In other 
words, an interruptible block will be called upon only if its strike price is at or below the ECP. The second proposal did not consider strike prices and had no impact on the ECP. The preference for this case was based on the belief that the first proposal could result in inappropriate spikes in the ECP or that ISONE may call upon interruptible loads prematurely (i.e., out-of-merit order) resulting in unnecessary and inappropriate inflation in the ECP. The argument maintained that, even if a small number of megawatts of load responded to the reduction request, it would be enough to link the price of such interruptible load to the ECP.

Since ISO-NE believed that an identified strike price was needed to attract interruptible customers, it strongly advocated the use of $200 \mathrm{MW}$ blocks priced at $\$ 500, \$ 750$, and $\$ 1000$ per MWh. The ISO-NE proposal provided that, when the ISO calls to interrupt a particular block, the price of that block would act as a floor to the ECP. Blocks would be called when (1) the forecast of the ECP would indicate a block to be "in merit" or (2) if Actions 1 through 12 of the Operating Procedure 4 (OP 4) [21] were implemented and the forecast ECP was not greater than the price of an interruptible block.

The NEPOOL Participants Committee (NPC) continued to explore the above issues and in an April 20, 2000 conference call, unanimously approved a final Load Response Program based on ISO-NE plan. The program would use specifically priced interruptible blocks that act as a floor price on the ECP with an added stipulation that this would occur only after Action 12 is implemented. (Action 12 implements a voltage reduction of $5 \%$ of normal - it is a serious condition but does occur occasionally.) Specifically, during OP 4 and before Action 12 is effected, ISO-NE may only call upon an interruptible block if its strike price (i.e., \$500) is at or below the ECP. Following Action 12, ISO-NE may call upon an interruptible block regardless of whether the ECP exceeds the price of the interruptible block.

Many features of the summer 2000 load response program are illustrated in Figure 3-1. Once customers sign up with a distribution company or load serving entity, actual interruption is voluntary. The amounts paid to customers who interrupt are based on arrangements made with the contracting Participant. Participants, whose load is reduced by an interruption by an interruptible customer, pay the difference between the hourly ECP and their lost energy revenue (i.e., from the interruption) multiplied by the estimated load reduction for that hour. Specific financial arrangements applicable to each interruptible customer are specified in the contracts between the participant and the customer. In order to increase

\footnotetext{
${ }^{13}$ OP 4, Action During a Capacity Deficiency, specifies Actions 1 through 15 that may be directed by ISO-NE to manage capacity deficiencies. The first 10 actions are designed to maintain full operating reserves while the last 5 are more extreme dispatch actions that may degrade system reliability and reduce the quality of service.
} 


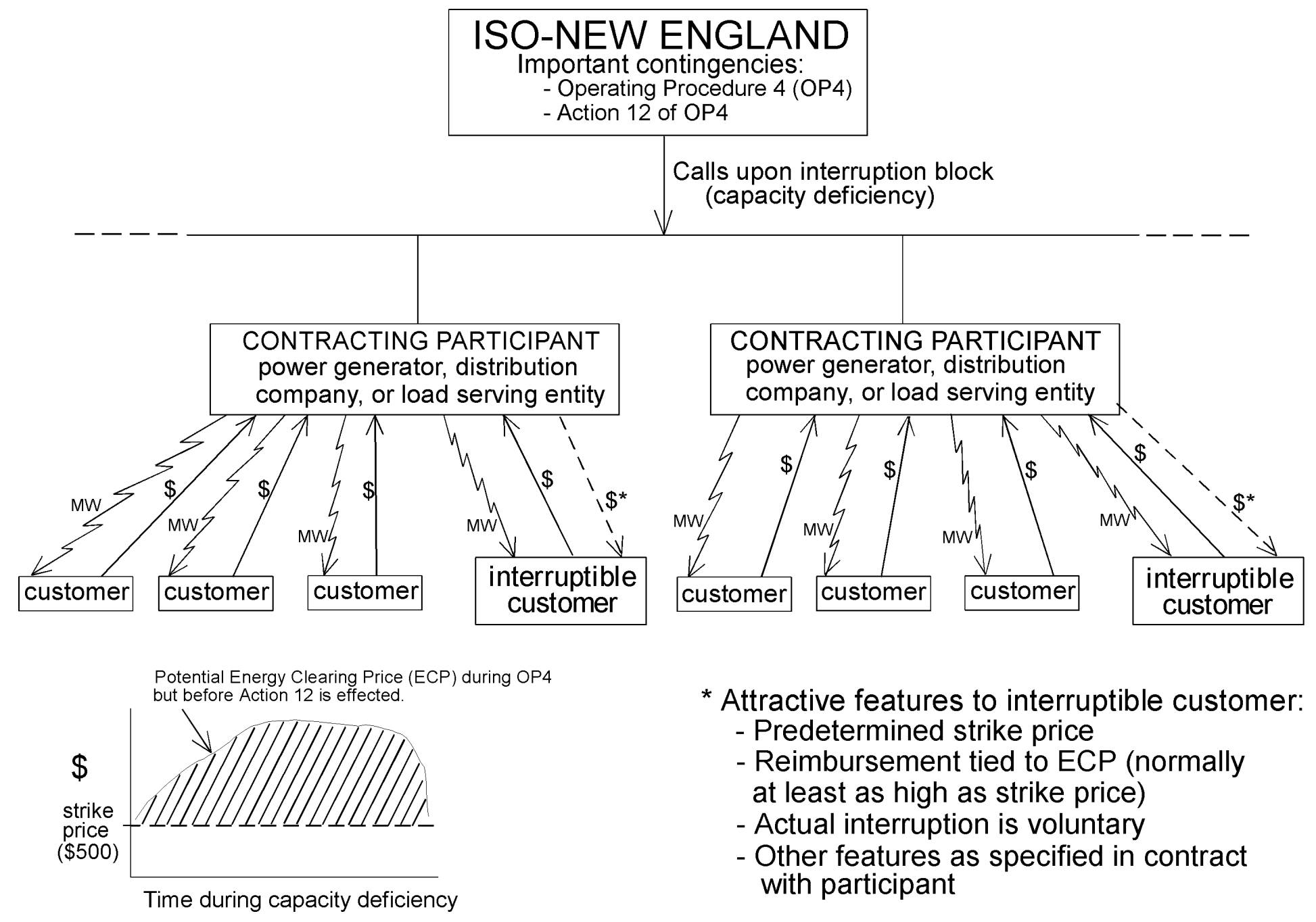

Fig. 3-1 ISO-NE load response program for summer of 2000 
incentives and encourage the solicitation of interruptible customers, excess payments (i.e., exceeding contract amounts) under the Program are kept by the contracting Participant. In addition, when full recovery is not made (i.e., Participant receives less than the amount it is obligated by contract to pay its customers), it must be absorbed by such Participants.

No actual power interruptions were necessitated in the program during the summer of 2000 because the weather was not very severe. However, it is encouraging to note that the program was sufficiently attractive to have enrolled or signed up several blocks with the potential capacity totaling: (a) $200 \mathrm{MW}$ in the $\$ 500 / \mathrm{MWh}$ block, (b) $6 \mathrm{MW}$ in the $\$ 750 / \mathrm{MWh}$ block, and (c) $7 \mathrm{MW}$ in the $\$ 1000 / \mathrm{MWh}$ block.

\subsubsection{Telemetering and interruptions (NEPOOL)}

Certain communications requirements have been developed to manage responsive load. Bids become invalid if loss of telemetry occurs during the time the load is called upon to participate in the market. In general, non-spin reserve bids submitted to an ISO must contain the time it takes to interrupt load following notification, the maximum allowable curtailment duration, and the demand available to be interrupted within a specified number of minutes.

NEPOOL requires Participants to telemeter the instantaneous MW value of dispatchable loads on a 10 second update. All telemetered load representations must be in whole MW values. [7] Each dispatchable load must have a dedicated voice communication telephone circuit to the single point of contact for ISO control of dispatchable load. Each dispatchable load wishing to connect to transmission facilities must have a valid interconnection agreement in place with the transmission provider.

Type 3 dispatchable loads in NEPOOL are those that are bid into the operating reserve market. They are interruptable by the ISO when operating reserve is needed, and must be interruptible an unlimited number of times each year. In order to qualify as 10 or 30 minute operating reserve, they must be interruptible within 10 or 30 minutes, respectively. The loads are selected in the respective operating reserve market based on their bid.

Type 4 dispatchable loads are those that are bid into the energy market. The loads are interrupted by the ISO based on economics using a \$/MW trigger. They must be available for interruption an unlimited number of hours each year, and must be interruptible within one 3-hr period from notification. They are interrupted by the ISO as needed based on their bids submitted in the Energy Market. The Participant's bid includes the dispatch lead time (maximum of 1 hour), load available for dispatch, and price. Type 4 dispatchable loads may also participate in the Type 3 market.

\subsubsection{Quantifiable load response program}

A new program has been initiated by ISO-NE that is designed to provide quantifiable load response capabilities at the click of a computer mouse. The 6-mo program that began in November 2000 will enable ISO-NE to rapidly interrupt power blocks of participating industrial and commercial customers when needed. The objectives of the pilot program are to demonstrate that a load response program can increase grid reliability and give major customers the ability to respond to electricity price signals in the wholesale marketplace. 
The pilot program will provide relief of up to 10-15 MW of load from certain NEPOOL suppliers such as NewEnergy Inc, and Select Energy Inc.; utilities such as National Grid and NSTAR; and large customer buying groups such as PowerOptions. In the event of a capacity deficiency that drives the cost of power high, these customers will be paid to reduce their power usage either by cutting back on their actual power consumption or through the use of their own on-site generators.

The quantifiable load response pilot program relies on an Internet application service called Load Management Dispatcher ${ }^{\mathrm{TM}}$, developed and marketed by Retx.com. The system tracks market prices at ISO-NE and provides automated notification to the energy service or load provider and customer when opportunities become available. The system is integrated in to ISO-NE's hourly energy trading platform, which streams real-time price signal to the energy company. The information is combined with the customers' energy usage and load management strategies to determine if an economic dispatch opportunity exists. With a click of the mouse, ISO-NE can notify customers of a potential power interruption. The customers then decide whether or not to interrupt their loads based on whether the energy price exceeds their thresholds (i.e., desired dispatch points).

The Load Management Dispatcher system records customer usage data via a meter data recorder installed at the customer's site. The system provides hourly performance data on each customer that is matched with the hourly clearing price. This data allows the ISO to accurately credit the customer financially.

Metered data is also recorded on the interrupted power levels for comparison with the operating reserve requirement. This data is of high importance to ISO-NE since it can be used a basis for lowering operating reserve requirements. The interruptible MWs can be treated as 10-minute, non-spinning reserves that provide enhanced system reliability in the NEPOOL wholesale market. Thus, it may be used to justify a reduction in generation resources committed for reserves.

In summary, there are 4 main advantages of the pilot program facilitated by a system such as the Load Management Dispatcher:

1. The retail customer can make an informed choice on whether to respond to prices in the market,

2. The ISO can assure improved system reliability,

3. Production costs can be reduced by justifying/operating less reserve, and

4. The environment is improved through reduced operating reserves (lower air emissions).

If the 2000/2001 winter pilot program is successful, an expanded Group Load Response Program is planned for implementation New England-wide in the summer of 2001. This program will be sponsored by the NPOOL Markets Committee and ISO-NE and is expected to be complete in April 2001. The likelihood of the expanded program providing actual benefits is much greater since it would be in effect during the peak season for electricity consumption.

\subsection{Load Participation in Electricity and Ancillary Services Markets of New Zealand}

In this final sub-section, New Zealand's reliance on loads to provide system reliability benefits is reviewed. As a response to the unique reliability threats to the New Zealand power system, New Zealand has operated a fast-acting emergency load shedding program since 1993. More recently, New Zealand has restructured its electricity system in ways that continue this program and expand the ways in which 
loads participate in New Zealand's electricity markets. To illuminate some aspects of these discussions, comparisons are offered to the CAISO.

New Zealand's generating capacity is dominated by hydro (about 60\%), which is predominantly on the South Island, but the country also has thermal generation (about 36\%), geothermal, and wind. Since most of the load is on the North Island (about 65\%), a high-voltage direct current (DC) tie, commissioned in 1965 and upgraded in 1992, connects the power systems of the two Islands. Its capacity is $1040 \mathrm{MW}$, a derating from its upgrade design capability of $1200 \mathrm{MW}$, and it operates at voltages of $270 \mathrm{kV}$ (north to south) and $350 \mathrm{kV}$ (south to north). The line stretches over $535 \mathrm{~km}$ of the South Island to the shores of Cook Strait, where it goes underwater to cross the $40 \mathrm{~km}$ between the islands. Failure of the DC link that connects the two Islands is a significant reliability threat. A second threat is that, because the North Island system is hydro dependent, the system relies on a small number of large thermal stations, a classic reliability risk. Note that the North island power system has low overall system inertia due to the inertialess $1040 \mathrm{MW}$ of DC inflow. Either failure of the DC link or an outage of a large thermal generator can represent a major disruption to the system, resulting in dramatic frequency excursions and, given the low system inertia, one that requires rapid remedy.

This fundamental reliability problem prompted heavy dependence on fast load shedding initiated by under frequency relays to protect the system. Note that this security scheme dates back to 1993, that is, since before the NZ electricity market was introduced in 1996. Since 1993, an emergency load shedding scheme based on the Fast Reacting Emergency Dumping (FRED) system has been in place [22]. Load is shed in 3 tiers: (1) direct shedding of interruptible loads (within 0.5 second), (2) emergency shedding based on under frequency relays (beginning at 1 second), and (3) further manual intervention as needed.

Clearly, the potential economic loss to a large load resulting from an interrupt that comes without warning and is triggered automatically and very quickly could be significant. On the other hand, transmission reliability being excellent overall, the risk of interruptions was historically small, less than one per year on average. To further stimulate participation, the electricity monopoly of the time offered significant incentives in the form of an interruptible energy payment. The payment was in the order of 50 $\mathrm{NZ} \phi / \mathrm{MWh}^{14}$ for all interruptible energy. Hence, this rate operated as a large customer subsidy, not unlike California's interruptible tariffs. There were some further sweetening conditions in the form of limits on the number and duration of interrupts. The only customers who could really benefit from this tariff were large industrials using electricity in heat processes; the largest charter participant by far (60 MW) was an iron smelter. Participation in the program had reached $150 \mathrm{MW}$ total by the time the newly restructured market began operation on 1 October 1996.

NZ's experience with load control is not limited to large industrial customers, however. Prior to the establishment of the open bulk power market, the wholesale cost of electricity to a retailer/distributor was determined by its annual peak demand while the retail cost to the consumer was based on energy consumption. Therefore, the retailer had an incentive to reduce peak demand while building load in demand troughs. One widespread and effective demand management technique used to achieve load leveling was to interrupt residential water heaters at time of peak demand. Interruption of domestic water heating is usually invisible to the consumer and so rarely causes an adverse reaction or decay in participation. Residential electric water heating is a much more significant load in NZ than in California.

\footnotetext{
${ }^{14}$ All amounts are given in New Zealand currency. At the time of writing 1 NZ\$ $=0.43$ US\$.
} 
In NZ, it often accounts for half of residential load, which itself accounts for half of average system load. Interrupts are initiated by power line carrier signals. This capability puts a remarkable tool in the hands of the distribution company, which could conceivably interrupt up to $10 \%$ of system load at any time, at least for a short duration.

\subsubsection{Market structure}

The electricity supply industry of New Zealand was restructured beginning 8 years ago by passage of The Electricity Act. Previously, a single government entity controlled the generation and transmission of electricity and local publicly controlled distribution companies owned distributors and retailers.

Under the restructured arrangement, the government retains sole ownership of transmission, which is in the hands of Transpower New Zealand Ltd, which acts as the system operator. Additionally, Transpower is responsible for ancillary service (AS) procurement, which is achieved both by contract and via an open market, with an increasing tendency to move towards the open market. Customers cannot self provide AS, as in California. The AS's offered in the Transpower market are defined very differently than they are in California's market. Notably, there are two reserve services, fast and sustained. The fast service requires a 5 second response time, and the sustained needs to activate in less than 60 seconds.

Generation consists of an open competitive market between four privately and three publicly owned major generators. Ownership is quite concentrated, the three public companies alone control about $60 \%$ of the market. Like California, wholesale competition in New Zealand operates both bilaterally through dispersed individual contracts between buyers and sellers, and through an autonomous centralized spot market called the New Zealand Electricity Market (NZEM). NZEM opened trading in 1996, and, while it is not a compulsory market, about $80 \%$ of all electricity deliveries are traded through it. That this market "... must not unfairly disadvantage new electricity technologies or demand side management," has been an explicit objective from its inception [23]. A price is established for each half-hour trading period by a simple merit ordering of generator offers. Bids and offers are received by hour 13:00 on the day ahead, and generators are dispatched in order of increasing offer price until the total demand bid is met [24]. Forecast prices are established at each of 244 nodes of the grid as the shadow prices resulting from a security constrained optimization. It is worth noting that this optimization process is for simultaneous cooptimization of energy and reserve offers. Thus, participants in the reserve AS market are able to influence the energy price.

However, these are not fixed prices, rather buyers and sellers are able to adjust their bids continuous up to a 2 hour deadline before real-time in hopes of achieving the schedule they like. The 2-hour shut off was a reduction from the original 4 , and NZEM has considered a further reduction. Transpower actually dispatches generators and operates the grid in real time, and actual settled prices are only known ex-post. At present NZEM is exploring a move towards real time pricing. The intention is to provide better price signals for parties to respond to in real time. In practice, and in contrast to the CAISO, Transpower acts as a single system operator, issuing dispatch orders to generators using the last set of offers, There is no obligation to supply, other than in accordance with the offers. 


\subsubsection{Load participation in the energy market}

Generators and loads cannot compete directly to be dispatched in the NZEM, as they do in California markets, although the possibility of including a dispatchable demand form of generator is currently under consideration. Only the generator representatives, known as Generator Class Market Participants (GCMP's) can offer energy for sale. Interrupts cannot be offered. However, some load participation in the NZEM is exercised through the demand side of the market. Purchaser Class Market Participants (PCMPs), which are only allowed to be active in the wholesale market, submit bids on behalf of electricity buyers. As noted above, based on day-ahead offers and bids, a pre-dispatch schedule is calculated and published, which market participants can review. Preliminary schedules are specified for all the 244 grid nodes at which the market is subsequently cleared. Note the pre-dispatch schedule is based on the bids and offers received, and not on a forecast of actual system loads. In other words, the prices established in the pre-dispatch only reflect how the market would clear if actual demand matches the total of offers made, which would only be a chance outcome. Additionally, in real-time, any imbalance that occurs in the bilateral market will also result in a change in the NZEM prices. All settlements are based on the actual ex-post price.

This arrangement allows for price responsive behavior as follows. Since, the offers and bids can be revised up to 2 hours prior to the actual half-hour market clearing period, PCMP's can revise their bids downwards to reflect the price responsiveness of its clients, if expected prices are high, and vice-versa. Also PCMPs can influence the final (ex-post price) by control of their load in real time. Some variation between bid and final load is permitted in the rules. Within this margin PCMPs may reduce load in real time in response to any sudden price spike that might appear in dispatch prices as the time moves towards real time. Such changes in price can arise form a number of reasons, such as loss of generation or transmission plant. An important component in this price responsiveness of load is the provision of dispatch prices. The Grid Operator provides these for 8 half-hour periods out from the current dispatch period. They are based on the current real time grid and plant configuration and actual load and an independent forecast of likely load in the next 4 hours. Thus providing a more accurate forecast of price nearer to real time.

In California terms, this would be equivalent to the scheduling coordinator self-dispatching load to repeatedly revise its schedule. It is through this mechanism that price responsive load is able to create demand elasticity and directly influence the outcome of the market. Note that this behavior is based on an actual forecast of load and prices and not on the pre-dispatch prices, which are only a snap market outcome that need bear little resemblance to actual conditions in real-time.

Indeed, a limitation of the current New Zealand trading arrangements is that the pre-dispatch prices deviate significantly from actual ex post settlement prices. Figure 3-2 shows an example of historic price deviations at one node, Haywards, which is the northern terminus of the DC link where a key marker price is set. However, note that the deviations have become damped over time, implying that the ability of market participants to anticipate prices is improving and they submit initial offers accordingly. The upper panel of Figure 3-3 shows the raw prices, rather than the percentage deviation at this same node, and clearly the correlation is improving. In fact, in the lower panel of Figure 3-3, which smoothes out the deviations by reporting only monthly averages, one can see that average forecast and ex post prices became within a $20 \%$ error band in the fall (i.e. March) of 1999 and have not strayed outside it since. 


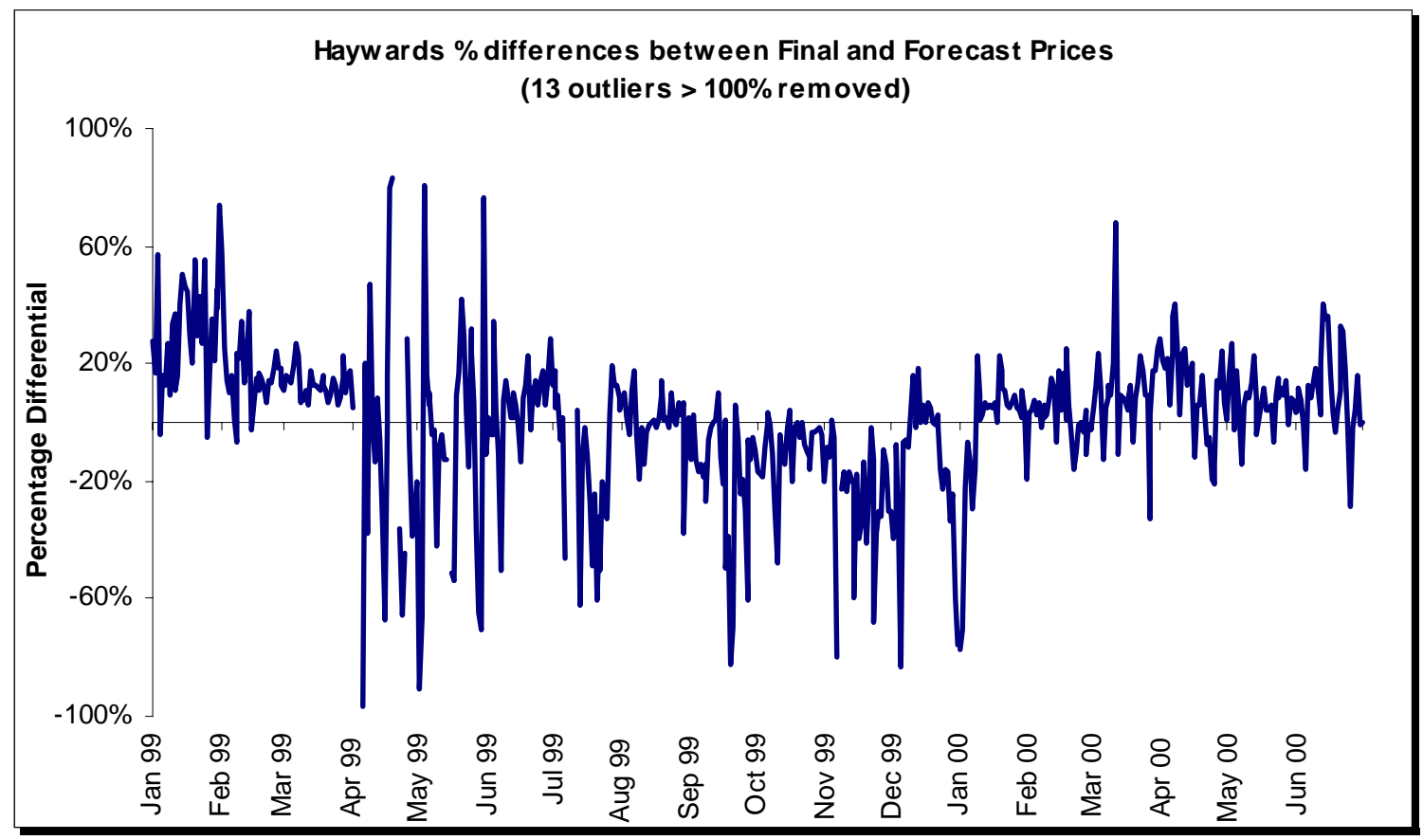

Fig. 3-2 Historic price deviations at the Hayward node [25]

Clearly then, while demand has opportunity to respond to a known forecast price, that price is only of limited value as an indicator of actual market clearing settlement price, and PCMP's are dependent on their own forecasts. One recent development that has proved valuable in this regard is the publication of dispatch prices as noted above. The figure below shows a comparison of the accuracy of dispatch versus forecast versus final prices. Current efforts under way are focused on the effort to deliver a more accurate price signal to ultimate users through PCMP's. One proposal under consideration would have the NZEM issue a deviation price as well as the pre-dispatch price. This would show market participants how deviations of various MW levels in actual real-time demand from the pre-dispatch total of offers would affect the actual clearing price. In other words, market participants would be armed with another forecasting tool on which to base their expectations of actual ex-post prices. In addition the move towards real time pricing mentioned above will again enhance the accuracy of the price signal.

\subsubsection{Load participation in ancillary services markets}

The establishment of the Transpower competitive AS market in 1996 changed the nature of AS provision. Target levels of AS procurement are calculated by Transpower based on a complex modeling effort that identifies the maximum contingency and determines what multiple of that capacity is required to ensure a secure system. The multiple can be both greater and less than one. Bidding into the two AS markets for fast and sustained reserve was by capacity and not energy. Offers initially came from two groups, the generators and the same interruptible loads that historically had been involved in the longstanding large customer program. Prices for these reserve services were coupled to the energy price in the same period, 

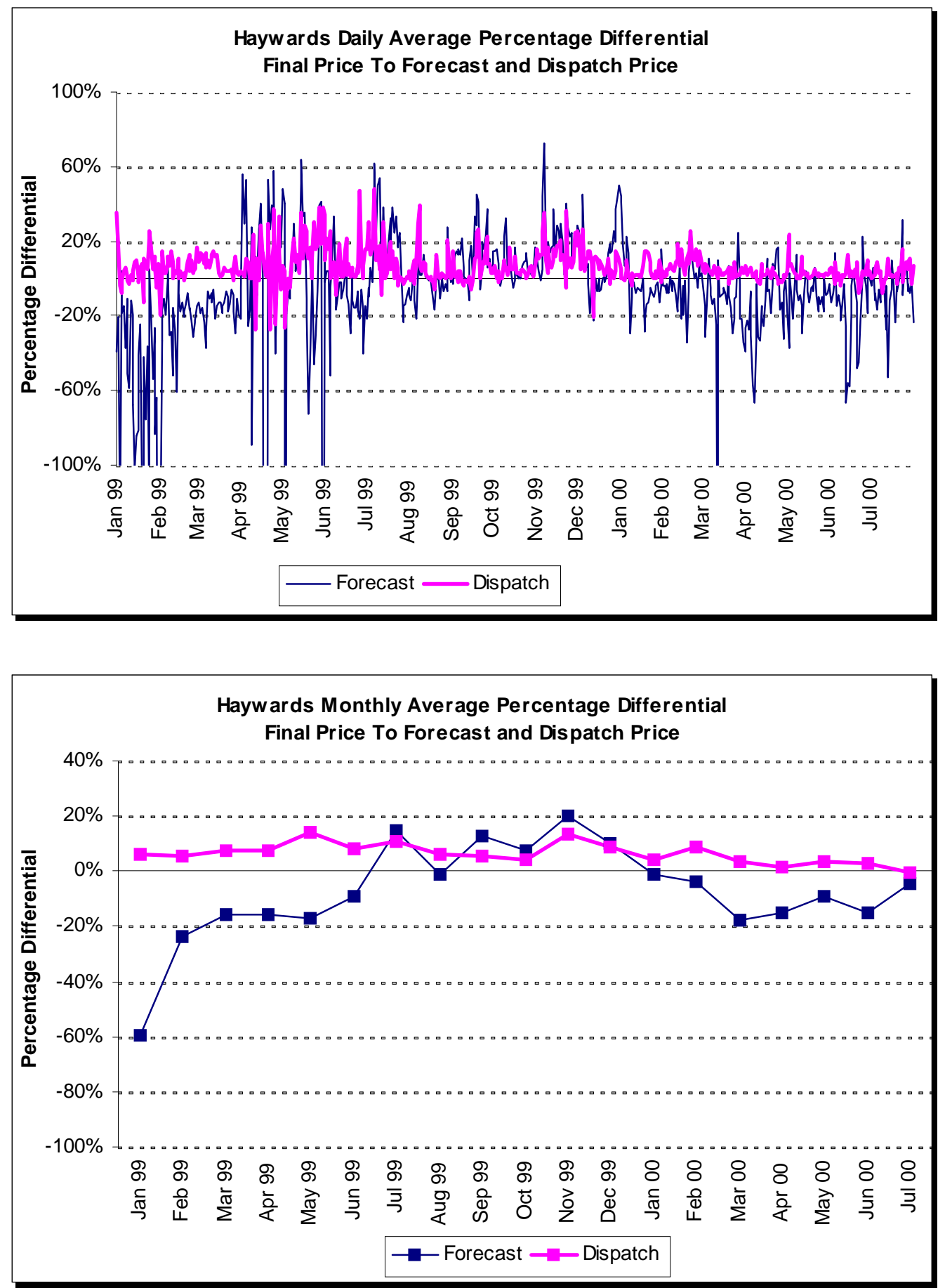

source: NZEM

Fig. 3-3 Actual prices at the Hayward node (monthly averages in $2^{\text {nd }}$ plot)

and were typically in the range of $10 \%$ of the energy price, i.e. about $25 \$ / \mathrm{MWh}$ for energy and 2.50 $\$ / \mathrm{MW}$ for reserve. This is a similar pattern seen in California because AS and energy are alternative products of the same generator suppliers [26]. 
The balance between large and small customer participation in the Transpower AS market has changed over time and the evolution of this market is the source of much of the mystique surrounding load participation in NZ. The risk of interruption has continued to be very low, and interruptions are automatically triggered by under-frequency excursions; that is, no communications equipment is involved and the cost of the needed undercurrent relays is relatively insubstantial. Consequently, smaller customers have realized they too could profit from participation in the AS market, because the frequency of interrupts is fairly low and the necessary equipment investments are generally manageable. One common form of participation is through split building air conditioning systems. Buildings owners will expose a fraction of their air conditioning equipment to interrupts but maintain enough capacity on firm power to maintain building temperatures within acceptable bounds during interruptions. The participation of these smaller loads that face quite a different and lower cost structure than the large generators and large customer loads has slowly eroded AS prices to the $50 \mathrm{NZ} \phi / \mathrm{MW}$ range, and, in fact, the market often clears at a zero price. In other words, since restructuring began, the cost of providing this service has fallen roughly by an order of magnitude.

Finally, the residential water heater program is still in place and operated by distribution companies. Customers who agree to the interruption equipment received a reduced tariff. One of the limitations of the water heater program often emphasized derives from its origin as a peak demand reduction strategy rather than as a backup service to generation. The triggering of interrupts is done at times of high demand rather than at times of system inadequacy, and occasionally now at times of high energy prices. While there is a strong correlation between high prices and congestion events, the match is not close enough to satisfy observers that the program is being used in a way that completely responds to the price signal the AS market is offering.

\subsubsection{Conclusions on the New Zealand market}

The NZ power system faces an unusual security risk arising out of its dependency on one intertie between its two islands, reliance on a few relatively large stations, and low system inertia due to the relatively large DC link and the large resistive load of an aluminum smelter. The system also suffers from weak transmission. These problems have been successfully addressed by aggressive load shedding programs that date back more than a decade, to a time well before the introduction of the NZEM. The two major programs prior to restructuring were fast response interruption of industrial loads based on the FRED system and under frequency relays, and a residential water heater program based on power line carrier signaling. These were centrally initiated interrupts and, at least in the case of the industrial program, like the California interruptible tariffs, it operated partially as a large customer subsidy.

At the time of restructuring, a competitive market was established for fast and sustained reserves, both of which are equivalent to a fast non-spin AS in California terms. As this market matured, small customers have entered it and driven prices down significantly, with great benefit to all customers through cost reductions. The roots of this success appear to be in the simplicity of the program, the low cost of the equipment required to participate, and the low frequency and duration of interrupts. The fundamental lesson for California appears to be that a simple and longstanding program can attract surprisingly levels of small customer participation. Longstanding is a key word here. In NZ, use of load shedding as a fast response AS has a decade-long history. Even small customer investments require some consistency of

rules and expectation of long-run returns. Competitive AS procurement in NZ also appears to have had a major cultural advantage in that reliance on load shedding has been a core strategy for maintaining system 
security for some time and familiarity with the concept was made very widespread through the water heater program. However, the AS being provided, most notably the low incidence of interrupts, and the automatic nature of its initiation based on system frequency is a fortuitous circumstance that does not exist in CAISO's markets. Notably no asymmetry exists between treatments of generators and loads because the signal to each is clearly visible in the system frequency.

As control of the water heater interruptible load is in the hands of the distribution company, it is still principally used in response to transmission demand spikes but is also available, to some extent, to respond to energy prices spikes. Actual operation of the program by a distributor depends on its contracts with retailers. The retention of control over an interruption program by the distribution company, which operates it in the interests of lowering its procurement costs, differs somewhat in principle to the California situation. In California, interruption of load is effectively triggered by the CAISO, although this may be achieved, in practice, through controller instructions to the distribution companies to shed load, first interruptible, then through rotating blackouts. Based on the expectation that the provision of demand-side services together with residential energy supply would quickly become contested markets after restructuring, California distribution companies were not encouraged by the California Public Utilities Commission (CPUC) to develop programs that would lower the cost of energy or AS price spikes. Further, as these costs were passed-through during the transitional period, the distribution company had little incentive to lower them, at least as long as collection of the Capital Transition Charge (CTC) was on schedule (i.e. until prices rose dramatically in 2000).

\subsection{Summary of Findings}

The following summarizes key observations regarding past and current load management programs:

1. The underlying communication, control, and metering technologies in existing utility load management programs, as well as potentially the program designs and operational procedures, themselves, represent important, yet currently un-appraised (and potentially undervalued), reliability assets for future competitive markets.

2. The California ISO's two load programs, called Ancillary Services Load Program (also referred to as the Participating Load Program), and the Demand Relief (DR) Program fell substantially short of targeted participation in the Summer of 2000. A key technical barrier for the Participating Load program was CAISO's stringent telemetry (4-second) requirements. A key institutional barrier for both programs was the limited time over which the programs were developed and implemented (programs were first announced in Jan./Feb. 2000).

3. Existing utility interruptible load programs already embody many characteristics that may be incorporated into future reliability-motivated load participation programs: (1) interruptions are triggered by a signal from the utility in response to system conditions; (2) customers have substantial discretion over the manner in which load is shed, in some cases including reliance on distributed generation (in contrast to direct load control programs that turn off designated pieces of end-use equipment); (3) customers at times have discretion over whether or not to interrupt at all; and (4) the utility already has procedures in place to verify interruption. Yet, there are significant unresolved technical and institutional issues, including observability (telemetry) issues on the one hand and the scope of utilities' retail activities (including operation of load management programs) in competitive markets on the other. 
4. ISO-NE's pilot programs and short-term load management solutions over time have had mixed results in reducing non-spinning reserve requirements. A key design feature of the latest program allows the retail customer to make an informed choice on whether to respond to prices in the market.

5. In New Zealand, use of load shedding as a fast response ancillary service has a decade-long history. However, the ancillary service being provided, the low incidence of interrupts, and the automatic nature of its initiation based on system frequency does not have parallels currently in U.S. markets. Loads also participate in New Zealand's energy markets as a result of a procedure that, in California terms, is equivalent to the scheduling coordinator self-dispatching load to repeatedly revise its schedule. 


\section{LOAD METERING, COMMUNICATION, AND RESPONSE TECHNOLOGY REVIEW}

The third phase of this assessment examines the status of the underlying metering, communication, and control technologies used to effect customer responses. The focus is on cataloging the technologies and approaches currently in the market. The scope of this review is somewhat broader than that covered in earlier sections of the report in that it includes technologies which would be applied to either price-based or system condition-based programs for engaging customer loads.

\subsection{Metering}

The function of the meter is generally quite simple, it must generate data that reflect the customer's energy consumption over some period of time. The length and number of time periods for which energy consumption must be recorded varies depending on the how the customer and the energy supplier choose to interact.

Energy Data of interest include:

- Energy - record the customer's energy consumption over the billing period, typically a month.

- Demand - record the highest demand (energy consumption over a 15, 30, or 60 minute period) as well as the monthly energy.

- Time-of-Use - record energy consumption in segregated time frames (bins) over the month. The timeframes are adjustable but typically do not change frequently. They are set to correspond to times when the system is typically experiencing high prices (on-peak) and low prices (off-peak) but can include gradations in between.

- Interval - record energy consumption every 5, 15, 30, or 60 clock-synchronized minutes.

Loads impose reactive power burdens on the power system as well as real power burdens therefore meters are also required to collect reactive power or apparent power data for larger customers. Though it is possible that some customers may some day enter into reactive power market transactions with the power system we do not address that possibility here and consequently treat reactive and apparent power as "other data" which the meter may collect.

Since advanced meters can potentially provide a communications gateway for the collection of other data, some have been designed to include features providing such a capability. This allows the cost of the meter and communications to be spread over more revenue-generating services. 
Other data that may be of interest include:

- Reactive or apparent power

- Power quality

- Voltage imbalance

- Loss of service

- Meter tampering

- Water consumption

- Gas consumption

- Alarm conditions such as flooding or freezing

\subsubsection{Review of interval metering}

An interval data meter is one that can provide not just $\mathrm{kW}$ usage, but a $\mathrm{kW}$ profile versus time. Nearly all load response programs, except those with direct control by the utility, require interval data meters. In many areas, interval data meters are required for all loads with demands greater than a certain threshold, say 20 to $50 \mathrm{~kW}$. The meters can communicate by phone line, or by a local infrared sensor that reads out the archived data to the meter reader.

Interval metering provides benefits not only for the utility in determining the impact of load reductions but also for the energy manager in checking for normal patterns of energy use. Some energy managers, when considering a load reduction plan, strongly prefer the use of an interval meter to assess the load reduction instead of using a historic profile to quantify the impact of a load reduction, because some loads such as air conditioning, are sensitive to temperature and other factors.

"Real-time" interval data can be made available to the user within a few seconds. The data is typically accessible at a password-protected web site. However, for most building energy managers and for utilities, actual real time data availability is not necessary. Daily, weekly, or monthly intervals are satisfactory. The meters may communicate the data using a variety of methods such as telephone, cellular phone, radio and fixed network (highest cost).

The cost of upgrading an existing meter to an interval meter is remarkably inexpensive, $\$ 90$ to $\$ 245$, if a phone line is already available [27]. New interval data meters range in cost from $\$ 200$ to $\$ 3,700$ depending on sophistication and features, such as true real time data updated every few seconds, and continuous power quality monitoring. Many new meters are designed to several different modes of communication, such as pagers or cellular phones.

Interval data meters allow energy managers to see an energy profile of a building and to evaluate the effects of operational changes such as control systems and compact fluorescent lamps. If the building demand can be shaped to fit the Energy Service Provider's best rates, large savings can be achieved by negotiating better prices. A hotel chain in California has found that when they use a cell phone to collect data from the meter, it costs less than $\$ 7$ per month. The same hotel chain pays a monthly fee for the interval data service. The quoted fees range from a low of $\$ 11$ to a high of $\$ 70$ per meter [27]. 
Another interesting feature of the new meters is the Real Time Pricing (RTP) input, which receives a communication signal from an ESP signaling the meter that a RTP rate is in effect. This signal then activates an extra data register in the meter, putting it into the RTP mode; the $\mathrm{kWh}$ data are then collected in the RTP register and are subject to the RTP price. The signal can be sent out by the Energy Service Provider, in response to a bid from the load owner or in response to some other contract vehicle.

One new meter, the MainStreet Internet Gateway, contains a 486 processor and $12 \mathrm{MB}$ of RAM. Once plugged in at the customer's meter base, it puts the building and the occupants on the Internet and enables the delivery of utility branded e-services [28]. It non-intrusively shares the customer's phone line, and it has a one-way Skytel pager for receiving information. As an option, it has a short hop RF wireless receiver for monitoring up to 16 sensors in the building. The customer has e-mail, real time price information, and a local web site with lots of other information. The service does not require a personal computer. The customer can view, manipulate and analyze his consumption data in real time. The wireless monitoring can monitor sump levels, system operation, temperatures, etc.

\subsubsection{Available technology for metering}

Meter Upgrade - An existing induction disc electro-mechanical meter can be upgraded to a full remotely readable interval meter. A pulse initiator is installed in the meter to generate an electrical pulse for every revolution of the disc by watching an optical mark on the disc. Pulse initiators cost range from $\$ 25$ to $\$ 45$. A data recorder counts the pulses and converts to energy consumption for the appropriate interval $(5,15$, 30 , or 60 minutes). The data recorder also contains the communications interface. Options on the data recorder include the number of channels it can accommodate (for watts, vars, water, gas, etc.), the amount of data it can store ( 5 minute readings for a month, for example), the number of communications ports (one for the energy service provider, one for the customer, and a third for outage notification), and the communications medium (telephone, radio, cell phone, two-way paging, etc.). Data recorders range in price from $\$ 80$ to $\$ 200$.

Advanced Meters - Four manufacturers dominate the electric meter market; ABB, General Electric, Schlumberger, and Siemens. Advanced meters from these manufacturers include the interval data collection and communications interface. Options with advanced meters also include the number of channels, the amount of data that can be stored, the number of communications ports, and the communications medium. Most new meters also provide a built in demand threshold alarm. Each manufacturer also offers meters that monitor power quality. Prices range from $\$ 250$ to over $\$ 3000$.

Itron provides meter modules that attach to utility meters to encode consumption and tamper information, then transmit the data to a remote reading device. The Itron modules that communicate via radio frequency are called ERTs and are normally installed under the glass of standard meters. ERTs can be installed by the meter manufacturer during the manufacturing process or easily retrofitted into most existing utility meters. Itron also offers telephone-based automatic meter reading technology. (www.itron.com)

Planergy, a load aggregator, requires that the loads they aggregate have 15 minute interval meters. These are supplied by the utility under tariff for $\$ 600-\$ 1000$. Planergy then adds a telephone-based data logger that costs $\$ 300-\$ 500$ from Silicon Energy, Inc. 
Utility.com, "the world's Internet utility", charges customers $\$ 144$ for an hourly interval meter though they say the meter costs them $\$ 249$. Southern California Edison will install an advanced meter starting at $\$ 475$ and $\$ 6.05 /$ month.

eLutions (www.elutions.com) has a range of devices available to interface between meters and the Internet or the telephone system. The Ethernet Pulse Input Module accommodates electric, water, gas or steam meters. It connects to $10 \mathrm{mbit} / \mathrm{s}$ Ethernet, TCP/IP via 10baseT network. Each module accommodates up to 6 single input pulse meters or 3 two-input pulse meters and can store 30 days of 15or 30-minutes interval readings. The GE-IP card interfaces advanced meters with the Internet with dual port access for the user and the energy service provider. The PM4000 uses commercial telephone lines to interface meters with the energy management system.

CellNet wireless system meters with the CellNet communications module communicate with a MicroCell controller located within about 1/3 mile. A CellMaster, located in the center of up to 200 MicroCells, links the MicroCells to the System Controller. If a utility only wants to automate the reading of 1,000 meters, it does not make economic sense to purchase a CellNet system. The CellNet system was designed for overall utility data communications, and becomes economical when used to replace the existing SCADA system and perform functions such as circuit breaker and capacitor control.

ITRON C\&I Network - the meters are equipped with modems that communicate by radio with a Hub; there are 50 to 100 meters per Hub. The Hub can cover a 5-mile radius. The Hub communicates with the host computer via a dedicated telephone connection. In a commercial corridor, the one-time cost per metering point is typically between $\$ 400$ and $\$ 500$. When the Energy Service Provider purchases the system, it owns the communications network. The only other cost is the dedicated phone line for each hub. The system can read interval meters from many manufacturers, and the basic system can support up to 10,000 meters. It can also receive calls from the meters to notify of outages or other conditions.

\subsubsection{Future technology for metering}

Further integration of data recording and communications into the meter itself will likely continue. This will likely be an evolutionary process. As with most electronic systems that gain acceptance and mature, hardware costs will likely decrease while functionality increases.

\subsection{Overview Of Communications Systems}

Several technologies are available for moving data collected by meters to the utility, load aggregator, energy service provider, or customer's central location.

The Power line carrier (PLC) sends communications signals over the power lines. This has the advantage that the communications network already exists directly to the meter.

Fixed Radio Networks place radio transmitter/receivers throughout the geographic area to be covered, typically mounted on utility poles or buildings. Each meter also has a radio transmitter/receiver. The network can communicate with any meter at any time. It provides the capability to support real-time 
energy prices, facility monitoring, daily meter reading, load profiling, time-of-use pricing, etc. Metering and sub-metering (non-billing) can give customers a better view of their facilities.

Mobile Radio Networks use technology that is similar to fixed radio networks except that the utility side transmitter/receiver is portable (either hand held or vehicle mounted) and used to make periodic contact with the meters. This reduces the cost of installing a fixed radio network but it also greatly reduces the ability of the system to support real-time operations.

Telephone Communications are also used to communicate with meters. The meter is supplied with a telephone modem. Communications can be initiated by the meter at set times or by the energy service provider whenever necessary. The meter can use a dedicated telephone line or can share the phone line with the facility. Meter modems are smart enough to recognize that the line is in use and try to make their call later. They can also recognize if a telephone is picked up while they are transmitting data. They immediately terminate their use of the line and try again later. If a standard telephone line is not available a cell phone $(+\$ 800)$ or a satellite phone $(+\$ 2000)$ can be used.

An advantage to telephone communications is that all of the loads in the aggregation do not need to be in the same geographic area. Another advantage is that no expensive infrastructure is required. A disadvantage is that communications take longer to initiate. It takes about $1 / 2$ minute to read each noninterval (monthly) meter. Reading 1 hour interval meters requires about 11/2 minutes each while 15 minute interval meters require about 4 minutes each when read monthly. These times are not long if you are reading a few meters but add up if you need to contact thousands.

The inherent differences between fixed network radio and telephone communications have interesting market structure implications. Fixed radio provides faster communications but it requires high geographic customer density. It is also cheaper when installed in mass. This gives it characteristics that are similar to the distribution system, it may be a natural monopoly. This could give the incumbent distribution company a significant technical and economic advantage in supplying advanced metering services.

\subsubsection{Automatic meter reading}

Utilities have been interested in automatic meter reading (AMR) for many years, independent of interest in responsive load. Much of the technology available today was originally designed with automatic reading, rather than load response, in mind. The benefits that AMR offers include:

- improved accuracy

- greater amounts of information, more than monthly energy and demand, can be collected

- overcomes bad weather

- reduces the need for estimated readings

- overcomes difficult access and dangerous situations

- theft detection

- automatic outage notification

Electric and gas utilities have 164 ongoing and scheduled AMR projects. The projects involve 12.4 million units. The systems that have, or plan to have, greater than 1 million units are: 
- Puget Sound Energy, 1.3 million

- Ameren UE, 1.3 million units using

- Northern States Power, 1.0 million units

- New Century Energies, 1.6 million units

The first three are using Cell Net fixed radio networks while the last is using a mobile radio system [29].

The current industry model for data collection and analysis involves several steps:

- data collection and on-site storage by the customers meter

- periodic data transmission to the energy service provider (or the energy service provider's agent) over the telephone (several types possible) or a private radio network

- data compilation and/or analysis by the energy service provider

- data presented to the customer over the Internet for customer analysis and action

Buffering the customer from the data adds value to the customer. The data is presented in an easily used format over a readily available medium. It also limits the interactions with the meter itself and thus protects the integrity of the data. This system works well for after-the-fact analysis but introduces communications delays for real-time response.

One option taken by some utilities is to let a metering communications company install and operate the meters and the communications network. It could then sell the information back to the utility and the customers.

Planergy, a load aggregator, uses this industry model. They use telephone-based data loggers from Silicon Energy, Inc. to record 15-minute interval meter readings. The data loggers are connected directly to a standard telephone line. If a phone line is not available, they add a $+\$ 800$ cell phone. If cell phone is not available they use a $+\$ 2000$ low-earth-orbiting-satellite commercial system.

Planergy uses the loads in its aggregation to respond to utility curtailment requests. When the utility notifies Planergy of the need to reduce consumption, Planergy notifies each of its loads and monitors their response. Loads that do not respond are contacted. Replacement loads are available to respond if necessary. Metering and communications are critical in establishing the response speed.

Planergy uses 15 -minute interval meters. There is a 15 to 30 minute delay from the initiation of the reduction until it can be verified by the meters, depending on when the request is initiated relative to the start of the next 15-minute (wall clock synchronized) demand period. Time is then required to collect the meter data. Because the telephone system has to make numerous calls to collect the data from all the customers the process may take 15 to 30 minutes. Data from the satellite system is via FTP but the Internet delivery system buffers the data so it also updates in about 15 minutes. The total time required from the start of the event until verification data is available is 30 to 60 minutes.

How we view these metering and communications delays may be critical. While it may take up to 60 minutes to verify performance the load reduction itself can occur within minutes. The power system receives the benefit as soon as the load is reduced, the benefit does not wait for metering and communication. 


\subsubsection{Available technology for communications}

CellNet provides data collection and data management services [27]. It uses fixed networks that it does not sell. Instead an energy service provider enters a long-term contract and CellNet installs and operates a network. A MicroCell Controller communicates via radio with up to 2000 CellNet communications modules placed on meters in a 1/3 mile radius (greater in rural areas). A CellMaster routs the signals from 200 MicroCells to the system controller located at a CellNet data center. The system controller converts the data to an appropriate format and presents it to the energy service provider over the Internet.

Itron provides a range of communications solutions [27]. They provide interface devices to connect meters to telephone, fixed radio, or mobile radio systems. They also provide the full communications networks that can be fixed radio, mobile radio, or telephone-based.

\subsubsection{Wireless communications systems}

This section will examine important wireless communications systems including:

1. cell phones,

2. Bluetooth system,

3. wireless LAN,

4. Home RF, and

5. the X10 product series

\section{Cell phones}

Cell phone technology is advancing from strictly voice to supporting a range of data applications. Many of these are applications are price sensitive. Price and metering communications may be an ideal fit in the not-to-distant future.

Ninety five million people in the US use mobile phones, resulting in wide (though not total) geographic coverage and volume-based cost reductions. Competing wireless networks employ different technologies for transmitting signals. Telecommunications companies are now working on third-generation (3G) wireless networks that could deliver data to and from mobile devices at up to $2 \mathrm{Mbps}$ [30]. The Wireless Application Network allows cell phones to talk to the World Wide Web. The server is operated by the wireless carrier, making the transition from the cell phone to the Internet. This is certainly faster data transmission than responsive loads require. Since the wireless carrier provides the server connection the infrastructure requirements for the energy service provider are greatly reduced. The problem of monopoly service provision is also eliminated since the wireless carrier can route each individual communication to any selected energy service provider without the delay of telephone system dialing. Cell phone carriers are beginning to address pricing of data communications as well. US carriers currently charge as much as 39 cents per minute. In Japan brief cell calls run about 20 cents but sending an e-mail message is about 1 cent.

Standards for wireless network components are advancing with the adoption of IEEE 802.11b last year. The cost of wireless network components has started to fall, also contributing to growth in wireless networks [31]. 
Bluetooth, wireless LAN, and home RF short-range wireless technologies

Several currently available wireless communications technologies may be useful for interconnecting the various metering, load, control, and communications devices that a price-responsive customer needs (See www.xircom.com). The advantage to this type of technology is that it, 1) avoids the cost of wiring these devices together, 2) provides a universal communications interface between various types of devices and various manufacturers devices, and 3) automatically reconfigures the communications network whenever a new device is added. This new device may include a computer, printer, etc. in the computing environment or a meter and/or load controller in the case we are contemplating here. Being young computer technologies, their performance will likely increase rapidly while their price drops assuming that production volume grows. Whether one of these specific technologies or another similar technology is developed, it is instructive to look at how the technologies work and what they can potentially offer.

Bluetooth is a short-range radio frequency technology operating at $2.4 \mathrm{GHz}$ and capable of transmitting voice and data 32 feet at the rate of $1 \mathrm{Mbps}$. It is an open architecture communications standard that was designed to allow mobile professionals to wirelessly synchronize and transfer data among computing devices. Bluetooth can be thought of as a cable replacement technology. Typical uses include automatically synchronizing contact and calendar information among desktop, notebook and palmtop computers without connecting cables. Bluetooth can also be used to access a network or the Internet with a notebook computer by connecting wirelessly to a cellular phone.

Bluetooth is extremely secure in that it employs several layers of data encryption and user authentication measures. Bluetooth devices use a combination of the Personal Identification Number (PIN) and a Bluetooth address to identify other Bluetooth devices. Data encryption (i.e., 128-bit) can be used to further enhance the degree of Bluetooth security. The transmission scheme (FHSS) provides another level of security in itself. Instead of transmitting over one frequency within the $2.4 \mathrm{GHz}$ band, Bluetooth radios use a fast frequency-hopping spread spectrum (FHSS) technique, allowing only synchronized receivers to access the transmitted data.

FHSS is a modulation scheme that uses a narrowband carrier that changes frequency in a pattern known to both the transmitter and receiver. Properly synchronized, they maintain a single logical channel. To an unintended receiver, FHSS appears as short-duration impulse noise. More simply, the data is broken down into packets and transmitted to the receiver of other devices over numerous "hop frequencies" (79 total) in a pseudo random pattern. Only transmitters and receivers that are synchronized on the same hop frequency pattern will have access to the transmitted data. The transmitter switches hop frequencies 1,600 times per second to assure a high degree of data security.

Different brands of Bluetooth products are compatible. The Bluetooth Logo Certification Program requires Bluetooth products to operate with products manufactured by other vendors.

Bluetooth radios operate on the unlicensed $2.4 \mathrm{GHz}$ frequency band (for Industrial, Scientific and Medical) that is shared among other devices (e.g., microwave ovens, cordless phones, garage door openers). Bluetooth radios switch frequencies at such a rapid pace (1,600 times per second) and the data packets are so small that interference from other RF sources is highly unlikely. Bluetooth is a robust communication system. 
Bluetooth functionality is ideal for a variety of cable replacement uses for mobile and desktop computing solutions and peripherals. Product manufacturers belonging to various industries (e.g., automotive, appliance, electronics) are in the process of integrating Bluetooth into their products. The Bluetooth Special Interest Group are companies working together to define and promote an open, royalty-free specification for seamless wireless connectivity.

Wireless LAN or WLAN is a wireless networking technology intended to augment or replace wired local area networks. WLAN is most frequently used in an enterprise setting for in-office network access. In contrast, Bluetooth should be regarded solely as a cable replacement technology. While Bluetooth uses FHSS as its means of communication, WLAN uses Direct-Sequence Spread Spectrum.

One of the most important distinctions between Bluetooth and WLAN products is that WLAN products are used to communicate with a network access point within an office or campus location. Bluetooth products communicate with other Bluetooth devices and not with network access points.

Home RF is also a wireless networking technology that operates on the $2.4 \mathrm{GHz}$ frequency band. The main difference between Home RF and WLAN is the data transfer speed; WLAN is faster than Home RF. Home RF is most often used in the small office or home environment. Table 4-1 compares the specifications of Home RF to those of both the Bluetooth and Wireless LAN.

Table 4-1 Short-range wireless technology comparison

\begin{tabular}{|c|c|c|c|}
\hline & Bluetooth & Wireless LAN & Home RF \\
\hline Frequency: & $2.4 \mathrm{GHz}$ & $2.4 \mathrm{GHz}$ & $2.4 \mathrm{GHz}$ \\
\hline Data rate: & $1 \mathrm{Mbps}$ & $11 \mathrm{Mbps}$ & 1.6 Mbps \\
\hline Range: & 32 feet $(10 \mathrm{~m})$ & Up to 500 feet $(150 \mathrm{~m})$ & Up to 150 feet $(45 \mathrm{~m})$ \\
\hline Standard: & Bluetooth & $802.11 b$ & $\begin{array}{l}\text { SWAP (Shared Wireless } \\
\text { Access Protocol) }\end{array}$ \\
\hline $\begin{array}{l}\text { Communication } \\
\text { Technique: }\end{array}$ & FHSS & DSSS & FHSS \\
\hline Usage Model: & $\begin{array}{l}\text { Cable } \\
\text { Replacement }\end{array}$ & $\begin{array}{l}\text { HighSpeed Network } \\
\text { Access }\end{array}$ & $\begin{array}{l}\text { Low-Speed, Low-Cost Voice } \\
\text { and Data Home Networking }\end{array}$ \\
\hline
\end{tabular}

\section{$X-10$ product series}

Another interesting local wireless communications and control technology with the advantage of high commercial volume and low price is the X10 series of products that allow a PC to control various appliances (X10 Wireless Technologies Inc., www.X10.com). This is not a robust, industrial-grade technology but it does perform required local communications and control tasks. It provides some insight into potential costs. 
The X10 system communicates through the existing power line to individually control a range of devices (i.e., up to 256 devices) such as:

- Lamp dimers and lighting controls

- AC sockets to control any device that is plugged in

- Appliances

- Thermostat to control heating and cooling

- Water heaters

They also sell a range of input devices so control does not have to be exercised from the PC keyboard. Prices range from $\$ 10$ to $\$ 40$ per device. The primary market is for convenience, security, and remote control. All of the functionality is present to allow control based on the price of power if such data are available to the PC.

\subsubsection{Future communications technologies}

Wireless communications systems represent an area that is likely to see dramatic development in response to a high demand/need. New spread-spectrum technologies for wireless communication over short distances should make it much easier and cheaper to interconnect meters to the telephone system, Internet, or fixed wireless network. They will also make it cheaper and easier for the facilities energy management system to access real-time meter data and to control loads.

The future architecture is likely to support direct, reasonably fast (i.e., relative to current practices) communications of real-time meter data to the customer to facilitate real-time decisions and control. This will require further standardization of meter-to-customer communications to allow interconnection of multiple vendors products.

\subsection{Communication Options for Load Control}

Communication needs for load control consist of two general areas of information transfer, one which must be made rapidly, within minutes, and the other which must be made more slowly, within days. The rapid communication is the signal to energize or de-energize the load, and the slower communication is to measure the response of the load, or the load profile. The rapid communication signal to control the load has traditionally been done by carrier frequency, radio or SCADA - all forms of traditional utility control.

In some cases, such as a simple hot water heater or air conditioner control, the second communication the response measure - may not be needed at all, because the utility can estimate what the coincidental load may be based on the number of de-energize signals issued.

In some cases, the rapid communication may involve a large amount of information, such as the bid price, and the customer's indication of the plan to curtail at a certain time and for a certain duration. In this case, the internet is proving to be a useful low cost alternative. The internet and local control of the load by the customer also empower the customer and give him the authority to interrupt as he sees fit depending on market conditions. 
The load profile is usually provided by an interval demand meter. The interval meter records the demand at short intervals of perhaps 1 to 10 minutes and either records the data so that it can be acquired later by the meter reader or transmits the data to a central location.

There is a range of communication and control options that are now available for load control that have recently dropped in cost and are readily available. These are discussed individually below:

- Telephone: If a telephone line is nearby, the installation cost is quite low, especially if it is to be a shared line. The cost for usage is medium if it is a dedicated line, and low for shared lines. Control and communication signals can be transmitted at any time for a dedicated line, there will be limitations on shared lines depending on the times.

- Cellular Phone: The telephone installation cost is relatively low compared to other communication systems installation costs. Rural areas may not be covered; but this will probably not be a problem because the loads that are most useful to control will be in high-density areas. Data collection and control can occur any time there would be limitations on communication times.

- Radio Communication: Private radio networks are now available at relatively low cost with low installation fees. Cost of usage is medium, comparable to a dedicated telephone line. Coverage is thorough in densely populated areas, but does not reach to some rural areas. Control and communication can occur at any time. One example is the ARDIS network that provides coverage in 427 Metropolitan Statistical Areas (MSAs). The radio network can interface directly with the meter or with a local computer-based controller.

- Combinations of Communication Systems Using Packaged Software: There are now windows based "do-it-yourself" telecommunications systems that provide real time data acquisition and remote control. One example is the SCADAlarm system from Wonderware. This is an inexpensive system that turns a PC into a communications and control center. These systems interface with telephone, cellular phone, and radio using inexpensive modules. They are designed to be user programmable. The installation cost is low, the cost to collect data is low, and data collection and control can be performed at any time. In addition, the system can easily be reconfigured or expanded by the owner.

- Small Scale Data Collection Systems: Data collection systems that interrogate meters and acquire and store the data are now available in small scales for energy service companies that are just starting to develop in a geographic area. Examples are ABB's Customer Site Metering System (CSM1000, for up to 1,000 meters) and Siemen's Energy Analyzer Plus (for 2,000 to 3,000 meters). Systems range from $\$ 35 \mathrm{k}$ to $\$ 100 \mathrm{k}$ plus the cost of the meters.

- Internet Based Market Programs: The most exciting aspect of communication and control that is developing in load management is the use of the Internet. The "Demand Exchange" concept has been created by a company in Atlanta called Apogee International. Day ahead forward curtailment prices are posted on a unique home page for each participant, and participants determine whether they wish to curtail and indicate their plans via e-mail. Their participation is voluntary and depends on their own business considerations. These demand reductions are aggregated by the "Demand Exchange" and essentially act as a supply alternative. The customers are the ones who actually do the de-energizing. 
This system was implemented by the Bonneville Power Administration and Entergy in the summer of 2,000 with surprising success. Several hundred MW were aggregated in a period of 2 or 3 weeks. One Energy Manager for a large national chain told the author that she only contracted with this program, even though she received 35 other offers, because this program gave her the decision to interrupt, gave her ample notice to decide, and had minimal costs to participate. Entergy pointed out that the greatest benefits are that there is no transmission risk and no worries about congestion.

- Internet Based Communication, Control and Metering Services: New services are now being offered that provide several features in addition to just Automated Meter Reading (AMR). These new services can make customers reluctant to leave when approached by a competitor. One example is MainStreet Networks, which provides a turnkey service using a new meter base with an integral computer. Data are transmitted by telephone, the Internet and radio for limited distances. MainStreet collects data at a central location and redistributes it to the utility in the needed format. In addition, information such as load profiles is also provided to the customer at a secure web site. Some of the

services that will be offered to the customer are low cost long distance telephone calls and monitoring of major systems and appliances with wireless sensors.

\subsection{Communications Systems Featuring Analysis Capabilities}

Many of the communications providers have designed into their systems the capability to provide meter data to customers for their analysis. Any number of graphical formats are available. Some provide the ability to directly compare costs that would result from various tariffs. Many allow the customer to download meter data into a convenient tool such as Excel for the customer to do his own analysis.

The following provides some examples of currently-available technologies:

Itron's MV-90 retrieves and processes advanced metering and load data for billing, load research and system engineering applications including aggregation, time of use, load research, interruptible rates, real-time pricing and Web access (www.itron.com). Itron claims that it can communicate with all advanced meters (multi vendor). The real-time pricing module maintains and transmits hourly pricing and load data to a utility's real-time pricing customers.

Active Energy Management (AEM) is a full-featured real-time Web-based energy information software product offered by eLutions (www.elutions.com). It integrates real-time pricing with energy consumption and provides for both analysis and control.

Silicon Energy's Enerscape software accommodates variable electricity prices and data from the energy management system. It can also be programed to utilize external information such as weather data. The customer can develop strategies that can be implemented from a central location using the Internet based interface. The analysis attempts to provide an integrated look at the customer's entire enterprise costs, with current electricity prices being only one component. Overall costs are then minimized based upon varying energy consumption. 
Honeywell has developed a software application, called RTP Controller, that works with its building energy management system, the XL building supervisor. This allows the user to perform what-if analysis and develop optimal response strategies.

Johnson Controls' Windows-based RTP software for its Metasys facilities management system allows the customer to input pricing data, develop a table of control decisions, and create up to four adjustable pricing thresholds, each specifying a set of load shifting or shedding actions.

C3 Communications' EnerACT remote monitoring and control service is capable of taking price information and combining it with consumption data to develop lowest cost scenarios for buildings.

\subsection{Customer Response to Communications}

The only objective for customer involvement in metering and communications activities is to facilitate customer response. That response may simply be to examine the data and conclude that no additional control activity is required. Hopefully, most customers will engage in more active control activities.

Customers can take four basic types of information-based action. They can take immediate manual action based upon current conditions. They can take immediate automatic action. They can invest in equipment and modifications to their facilities that reduce their energy cost. They can invest in equipment and modifications to their facilities that give them flexibility to respond to future events in real-time. The first response requires little capital investment and can be effective if the number of events is not too great. The second (i.e., automatic response) accommodates numerous events but involves greater cost.

One profitable application of interval meter data does not require rapid communications. After-the-fact analysis lets customers analyze their operations and reduce their energy costs. They can find broken controls that leave heaters or pumps on all the time. They can identify high-demand buildings and determine the cause. Knowing which facilities are using large amounts of electricity and when allows customers to focus on those specific aspects of their operation and take actions to reduce costs. Customers can then take actions changing procedures, equipment, or both that result in a continuous improvement in energy consumption and load shape with a corresponding reduction in power cost.

Demand meters can also be used for load control and cost reduction without rapid communication with the energy service provider. The meter can provide a signal when a demand limit is being approached. That signal can be used to automatically curtail non-critical loads or to provide an alarm to facility operators to manually reduce consumption.

One interesting response to real-time prices is to analyze a load's current performance, decide to move to real-time pricing, and take no active control actions. This can be rational if the resulting average energy cost is below that which the customer would pay under a more conventional tariff. Dayton-Hudson, parent company of target department stores, has taken this approach in several locations [32,33]. They fear that load management in response to electricity price fluctuations would interfere with customer comfort.

Customers interested in engaging in real-time energy markets need to know the real-time price. Most customers would also like to know their real-time consumption. It may be that most control actions will 
be taken during the 100 - 200 highest priced hours of the year. Typically price duration curves are steep at the high-priced end, tending to confirm this assertion. If that is the case as emerging energy markets develop it implies that manual control may continue to be effective for some larger loads. It also implies that the disruption caused by any control (automatic or manual) will be limited.

Planergy, an aggregator of larger loads, does not have any customers using automatic control, and the customers view this as a selling point. There is great reluctance for the customer to loose control of its process. Clearly these customers do not view the automatic control as implementing their instructions, they view this as an intrusion by the utility.

Data communications does not have to be an obstacle if the load is being controlled from the metered facility and if the meter can support communicating with at least two users, the local facility manager (or automatic control equipment) and the energy service provider. In that case the meter can provide real-time consumption data for load control and simultaneously report interval meter consumption to the energy service provider daily, weekly, or monthly.

\subsubsection{Available technologies facilitating response}

Cannon Technologies has over 250 load control systems installed at municipal, rural, and investor owned electric utilities [34]. Their loadcontrol.com system reduces the infrastructure burden for the energy service provider (www.cannontech.com). Cannon creates a private load control Master Station on their server. They can set up strategies to cycle many loads such as appliances, control generators and irrigation wells. Communications from their server to the loads is via $900 \mathrm{MHz}$ FLEX $^{\mathrm{TM}}$ national paging. By integrating the system with real-time meter data collection using their companion service; readmeter.com, they provide a complete system for monitoring and controlling demand anywhere in the country.

The LCR 5000 load control receiver embeds a control message in a pager message. A single pager ID is all that is necessary to control any number of LCRs. Therefore, the utility does not require a communication infrastructure for load control. FLEX ${ }^{\mathrm{TM}}$ paging is available worldwide and messages are not limited to a utility's service territory. No equipment or software is needed by the paging provider.

Cannon offers other options for load control communications:

- VHF radio (traditional licensed frequencies)

- EMETCONTM Distribution Line Carrier (utility owned digital communication)

- FM/SCA (commercial FM radio simulcast)

- $\mathrm{ABB} \& \mathrm{BBC}$ Ripple carrier (low frequency line carrier)

Features of the load control receiver (LCR) include:

- Remote addressing and configuration

- Up to 3 relays, each operating independently

- Programmable "cold load pickup" for each relay

- Remotely disable an LCR or any of its individual relays

Utility Data Resources utilizes telephone communications to transmit pricing and usage information to customers on a routine basis. It can also handle load reduction/curtailment. RTP customers can be 
maintained with the PowerPrice software in either of two scenarios, a flat reduction of firm load level, or a percentage basis of firm.

Utility Data Resources uses MV-90's load control products. To utilize the MV-90 load control software, a dedicated computer is required at each customer site participating on the interruptible tariff. The MV-90 $\mathrm{L} / \mathrm{C}$ Station software is an informational and communications tool used by the host utility to notify its load control customers of a scheduled interruption or emergency situation. Communication is through a voice grade telephone line using a standard analog modem. Load control customers are notified of a scheduled interruption or emergency situation by an audible alarm and a message, which is displayed on the customer's monitor. The L/C Station software also polls the customer's load profile meter and displays the demand data in graphical or tabular format. The polling process allows the customer to track its usage in relationship to its interruptible contract.

eLutions' (www.elutions.com) Active Energy Management (AEM) system provides the software for control actions. Their Building Server allows the AEM software to communicate with intelligent serial-based devices such as chillers and HVAC equipment, circuit breakers, generators, uninterruptible power supplies (UPS), and programmable controllers.

Honeywell's RTP Controller analysis software works with its building energy management system, the XL building supervisor, and implements strategies the customer has developed for building optimization under different dynamic rate thresholds. As variable prices are retrieved via FTP, bulletin boards, e-mail, or Web sites, the application responds by automatically executing the appropriate strategy for the newest rate.

Honeywell has also developed a residential and small commercial programmable thermostat, the EMS 1000 , that can receive and respond to pricing information.

C3 Communications' EnerACT remote monitoring and control service can adjust a control setpoints throughout a facility in response to dynamic price signals. The target market is companies with more than 40 sites each of which has an annual utility bill of at least $\$ 50,000$.

\subsubsection{Future technologies facilitating response}

Most current applications aim at curtailing loads for extended periods of time, generally for several hours throughout the daily peak. This is difficult for many customers. It is much easier to store 10-30 minutes of thermal energy or process inventory than it is to store several hours worth. If rules could be changed to allow loads to provide spinning and non-spinning reserves, and if fast control technologies can be implemented to genuinely provide the service, many more loads would likely enter the market. This would free up generation to generate rather than to stand in reserve. 


\subsection{Summary of Findings}

Key findings regarding communications and control technologies are as follows:

1. A wide array of advanced power meters is now available that provide reactive/apparent power, time of use data (i.e., in segregated time frames), interval date (i.e., KW vs time), and special communications features that operate via phone, radio, or power lines;

2. Wireless data communication systems for metering, load data, control functions, etc. provide adequate speed and advantages of universal communications interfaces, automatic reconfiguration as new devices are added, and security features such as data encryption and user authentication;

3. The Internet and local load control by the customer empowers the customer by giving him authority (and the necessary information) to interrupt based on his preferences and market conditions;

4. Available load control communications systems feature advantages including, (a) using the $\mathrm{PC}$ as a communications and control center, (b) interrogating meters and storing data, (c) using the Internet to provide day ahead curtailment prices, and (d) analysis capabilities; and

5. Customer response can be aided by systems that provide real time prices, both automatic and manual control, and control of set points throughout a facility that respond to dynamic price signals. 


\section{PLANNING AN R\&D AGENDA}

This final section outlines a vision of how the future might look and uses it to outline a program of needed $\mathrm{R} \& \mathrm{D}$ to increase the role of customer loads as an essential system reliability resource.

\subsection{How Might The Future Look?}

In the future, the reliability benefits of customer response to market prices will very likely become increasingly important. In the long run, the distinction between reliability and markets will diminish as system operators rely more and more on markets to obtain reliability services. Specifically, high prices will signal impending reliability problems. A focus on prices, rather than on strict reliability rules, will provide much more flexibility and incentive to customers to save money, automatically improving system reliability.

In this future projection, residential load will be considered since it represents the most difficult load to make responsive (i.e., electricity cost is not a major consideration and the "operator" does not want to be inconvenienced). It is likely that fully automated load management/metering systems could be economically justified given the maturation of the technology and the important benefit of high-volume production.

Major features of future residential meter and utility communications may be as follows:

- Accepts price signals from the utility.

- Accepts deployment commands for ancillary services.

- May have internal frequency reference to generate frequency responsive command for spinning reserve.

- Records electricity consumption vs time based upon market interval.

- Records ancillary service response.

- Reports response back appropriately. This should not require real-time reporting back from each residential load but could if the utility insists on it.

- Meters with Internet connections will allow customers to make their own interrupt decisions in a day ahead market (or other market) based on market conditions and their own needs.

Desirable features for internal communications:

- Wireless communications should be employed between the meter and the customer's "control center" and between the control center and any responsive loads.

- Communications should be plug-and-play. That is, when a new responsive device is brought into the home it negotiates with the control center without user involvement.

- Communications from the responsive loads to the control center should include 1) device electrical size, 2) response rate, 3) response duration, 4) any other restrictions on operation, 5) current status, 6) manual override 
The Customer's Control Center would be an intelligent box performing tasks that are only slightly more sophisticated than those required from a calculator:

- Receives price signals and deployment commands from the electric meter.

- Knows the capabilities and status of each responsive load.

- Interfaces with the owner to know the owner's general and current preferences for price sensitivity. This can be through a direct Control Center Interface for some general information and from each responsive load since it is more natural to collect the information there.

- Provides user feedback through a combination of methods. 1) A PC interface to allow thorough review of costs, savings, individual load response, individual load performance/value. 2) An immediate feedback display of current cost/savings (e.g., current day, week).

Intelligent Appliances - As intelligent appliances become available they will incorporate energy cost as one variable. Each will communicate with the Control Center. An appliance, such as a refrigerator, could be made smart enough to know if it can tolerate a 10-minute interruption of the compressor to sell spinning reserve. This would be based upon internal temperature and, possibly, learned expected usage based on time of day. The appliance would also communicate its capabilities and current status with the Control Center. The Control Center and Intelligent Appliance may even negotiate a change in appliance behavior based upon current power and ancillary service prices. The refrigerator might lower its temperature 3 degrees if the price of spinning reserve is high enough, for example, allowing the refrigerator to enter that market.

Candidate Intelligent Appliances include:

- Refrigerators - ancillary service markets and possibly energy markets. Probably no user direct input. Possibly "learns" owner's behavior and preferences.

- Hot water heaters - energy and ancillary service markets based upon "state of charge." Possible direct user input telling the hot water heater that guests are present $\&$ the owner does not want to risk running out of hot water.

- Dryer - energy and ancillary service markets. Direct user input if waiting is unacceptable at this time. User should be less sensitive to a spinning reserve interruption than to an energy interruption.

- Washer - similar to dryer.

- Heat Pump, Central AC - energy and ancillary service markets. Possible separation of compressor and fan loads. Otherwise same as thermostat.

- Thermostat - energy and ancillary services. Direct user interface that is likely to be in the form of Degrees-offset/\$-per-day-saved. It only adds 1 additional dial to the thermostat and the user can override it at any time.

Responsive Controllers - Some appliances will be built intelligent, such as refrigerators. When intelligent appliances are not available, much benefit can be obtained from separate Responsive Controllers that control power to appliances. Performance will not be quite as good as with an intelligent appliance. A Responsive Controller for a refrigerator, for example, would probably not respond to internal temperature or reduce temperature in anticipation of selling ancillary services. It could not decide when it had to drop out of real-time energy markets, for example, based upon internal temperature. It would have to use a conservative assumption based upon near worst-case usage (e.g., door openings). Also, the user would notice that the light does not come on when the Responsive Controller had the refrigerator curtailed. 
There would probably be less of a distinction with a load such as a dryer.

Degree of load control - Table 5-1 presents energy consumption for appliance in a typical residence. Note that these numbers are energy rather than power. That is, they represent the average annual power consumption for each appliance. This is a better number to use than the actual power consumption because the power system is interested in the aggregated response it would get from a large population of similar customers. These numbers are, in fact, conservative because the power system values energy and ancillary services most when system load is high and more appliances will normally be cycling on during times of high consumption.

Based upon the figures presented in Table 5-1 [35] a typical residence would have between 1 and $2 \mathrm{~kW}$ that could participate in the ancillary service markets and be price responsive in the energy market. One million price responsive residential consumers would provide 1000 to $2000 \mathrm{MW}$ of available response.

Table 5-1 - Typical residential load energy consumption and potential for price response

\begin{tabular}{cccccc}
\hline $\begin{array}{c}\text { Avg } \\
\text { power } \\
\text { (W) }\end{array}$ & Load & $\begin{array}{c}\text { Potential Market Participation } \\
\text { Real-Time } \\
\text { Energy }\end{array}$ & $\begin{array}{c}\text { Frequency } \\
\text { Responsive } \\
\text { Reserve }\end{array}$ & $\begin{array}{c}\text { Supplemental } \\
\text { Reserve }\end{array}$ \\
\hline (see & $15 \%$ & Air Conditioning & Yes & Yes & Yes \\
HVAC) & $27 \%$ & Space Heating & Yes & Yes & Yes \\
\hline 900 & $42 \%$ & HVAC & Yes & Yes & Yes \\
207 & $10 \%$ & Refrigerator & Some & Yes & Yes \\
301 & $14 \%$ & Water Heater & Yes & Yes & Yes \\
604 & $28 \%$ & Appliances & Some & Some & Some \\
144 & $7 \%$ & Lighting & No & No & No \\
\hline 2157 & $100 \%$ & Total & & & \\
\hline
\end{tabular}

A residential customer with an emergency backup generator or a cogenerating microturbine would have even more opportunities to automatically participate in the energy and reserve markets. The operating cost of the generator would be compared against the purchase and sale prices for electricity. The combination of instantly interrupting thermal loads, starting the generator, and restoring the load could convert an idle generator into a very reliable source of spinning reserve.

Future success - Achieving this future depends upon overcoming a number of formidable barriers. Equipment prices must be reduced. The tasks each piece of equipment must perform (e.g., communications, computation, control) are not particularly difficult or complex when compared to the functions other consumer devices perform such as pagers, cell phones, calculators, PCs or VCRs. Clearly the key to reducing costs is increasing the product volume. This is not a fundamental obstacle; there are tens of millions of potential users.

High volume does require that the same equipment can be used in a wide market area. Service definitions must be sufficiently standardized across the nation that unique equipment is not required in each control 
area. These rules should be technology neutral, specifying the required response rate, for example, rather than that the response must come from generation of a specific type. This should be possible without constraining the required variation in service parameters needed to accommodate differences in regional power systems.

If this type of response can be imagined for residential customers it can be achieved much sooner for commercial and industrial customers where metering, control, and communications costs can be spread over higher levels of energy consumption per device.

Generators, distribution companies, and energy service providers that encourage this move to the future will likely profit from it. Customers will require assistance for critical parts of the infrastructure. These systems also require aggregation to achieve sizes that are truly valuable to the power system. A portion of the profits generated by the customer actions should flow to those that facilitate the capability.

The lack of standard market rules is likely the single largest obstacle to expanding responsive load. Honeywell developed an RTP controller package for use with its building automation system and was testing it in the Marriott Marquises and the World Finance Center in New York City. Savings of 10-20\% were achieved over their previous energy cost. This was a $\$ 400,000$ per year savings for the Marriott. But Con Edison canceled its RTP program in January of 1998 and the RTP feature could no longer be used. Both the users and developers of these systems run economic risks unrelated to their physical performance or that of the electricity market based simply on a rule change. Under these conditions new systems will not be developed and production volumes will not increase as required to reduce costs.

Many customers that have become price responsive have had more difficulty integrating their systems than they expected resulting in higher-than-expected implementation cost. The lack of industry wide standards at all stages of the dynamic pricing process has made development of automated response systems expensive. There is also no standard for smart appliances to be able to talk to smart controllers that can talk to smart meters. This is compounded by the fact that, inherently, there's a need to drive down to smaller and smaller customers. While a custom-designed automated response system for a $1000 \mathrm{MW}$ resource may be viable it is not practical for a $1 \mathrm{MW}$ or $10 \mathrm{~kW}$ resources. Price-responsive-load technology inherently needs high volume to bring cost down. Fortunately, communications standards for meters, control devices, and the wireless Internet are all developing, though slowly.

\subsection{Outline of an Integrated Research Agenda}

In view of the issues raised in this scoping study and the possible future outlined in this section, a multifaceted research agenda is required to address both the institutional and technical challenges. The remainder of this summary provides an outline for some of the key elements of such an agenda.

Address the Information Needs and Control Requirements of System Operators - The recognition that power reduction via load management cannot be measured is most pronounced from the standpoint of electricity system operators. One cannot manage what one cannot measure and current systems for managing electric system reliability are predicated on large generators with measurable outputs. Modifying operational control systems to accommodate load reductions on an equivalent basis with electricity generation poses a series of challenges. First and foremost, the underlying system reliability 
rules and practices underlying current telemetry requirements and control procedures must be reviewed and redefined from a technology-neutral point of view, yet without compromise to the management of system reliability [36]. Second, new communication and control technologies consistent with these redefinitions must be developed and implemented. For the most part, we do not envision new fundamental R\&D in sensor, communication, and control technologies, but instead new forms of integrating existing technologies consistent with the management of customer's loads, as reliability resources.

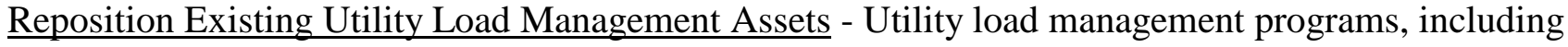
direct load control, interruptible load, and real-time pricing, constitute a large installed base of controllable loads that in principle should be considered system reliability resources. The underlying communication, control, and metering technologies, as well as potentially the program designs and operational procedures themselves represent important, yet currently un-appraised (and potentially undervalued), assets for future competitive markets. In the short run, modified and improved operation of these programs may be the most effective form of demand-side response available to the electricity system today. Existing assets must be carefully scrutinized in light of recent technological advances and incremental investments considered. In the long run, continued utility operation of these programs must be evaluated in the light of regulatory questions regarding the scope of regulated and unregulated utility activities in future markets for retail energy services.

Accelerate the Transfer of Emerging Program Experiences - Utilities and ISOs around the country are currently engaged in nascent efforts to develop programs that attempt to tap customer load management activities explicitly as a reliability resources [37]. Maturation of these programs would be accelerated by greater sharing of program experiences among current and other potential program sponsors and market participants. For example, creation of competitive markets for the provision of retail energy services has led to entry by load aggregators that serve as market intermediaries between individual customers and system operators. By virtue of representing aggregations of customers, these entities can in principle internalize and spread the performance risk associated with reliance on individual loads and thereby guarantee minimum levels of performance to system operators. Similarly, by serving as a single point of contact for system operators they may also reduce system communication, control, and metering requirements (again, by internalizing them). Understanding the market niches served and overall business strategies employed by these new entrants is critical to ensuring uniform and fair market rules to guide their participation in the competitive electricity market place.

Pioneer Promising New Program Design Concepts - Real-time pricing is often mentioned as a necessary condition for enabling meaningful customer participation in competitive markets. And, indeed, developing second-generation real-time pricing programs consistent with the design and operation of current competitive electricity markets should be a high priority [38]. However, in addition, there are many other worthy program design concepts, such as priority service, that should also be explored. The basic observation is that customers are incredibly heterogeneous in their preferences. For example, some customers may prefer to view provision of their loads as system reliability resources simply as a new profit center. Still others may be willing to offer their loads only in response to true system emergencies. Many customers will require substantial advance notification, and will want to limit the duration and frequency of interruptions; others will be substantially more flexible. Enabling widespread customer participation will require substantial creativity. We should not be surprised to learn that (and therefore should foster the development of) a multiplicity of approaches is required to effectively target and extract the full potential load as a system reliability resource. Consumer market research, coupled with 
experimental economic approaches, is needed to quickly and inexpensively develop and test promising new approaches.

Incorporate Grid Reliability Considerations into the Design and Operation of End-Use Technologies Today, few end-use technologies have been designed with any consideration for their impacts on grid reliability [39]. Many, such as induction motors and various power electronics devices, are in fact wellknown for the special challenges they create for reliable grid operation. As grid reliability services become unbundled and traded in competitive markets, the true costs and value of these currently externalized impacts of end-use technologies will be revealed. As a result, an environment for the redesign of and new controls for the operation of end-use technologies will emerge. Still, there remain substantial institutional challenges in linking system reliability needs to manufacturer's end-use electricity product offerings. Some have suggested that government standards on frequency and voltage response may be required to cement this linkage. Regardless of the specific institutional pathway, there is need for enabling research to improving our understanding of the grid reliability impacts of end-use devices, and to identify technical options to modify these impacts.

Disseminate Technology and Programmatic Solutions through Demonstrations - Research will only bear fruit when it is demonstrated and refined in the real-world market and operating settings. Therefore, an integrated program of research must include R\&D demonstrations as a necessary element. The demonstrations must address the real-world situations faced by system operators and market participants today. Engagement with these stakeholders to identify the specific needs for prototype solutions must remain the cornerstone of a successful $\mathrm{R} \& \mathrm{D}$ program. Once needs are established, these stakeholders must also assist in implementation. 


\section{ACKNOWLEDGEMENT}

The work described in this report was coordinated by the Consortium for Electric Reliability Technology Solutions on behalf of the Assistant Secretary of Energy Efficiency and Renewable Energy, Office of Power Technologies of the U.S. Department of Energy under Contract Nos. DE-AC03-76SF00098 and DE-AC05-00OR22725, and the California Energy Commission Public Interest Energy Research Program under Award No. 150-99-003.

\section{References}

1. B. J. Kirby and J. D. Kueck, "Review of Bulk Power Markets," Lockheed Martin Energy Research, Oak Ridge National Laboratory, Oak Ridge, TN (1999)

2. S.J. Battles, Electricity Generation in the Manufacturing Sector: A Historical Perspective, 20th Annual North American Conference of the United States Association for Energy Economics, Affiliated With the International Association for Energy Economics (August 1999)

3. B. J. Kirby and J. D. Kueck, "How Buildings Can Prosper by Interacting with Restructured Electricity Markets," Oak Ridge National Laboratory, Oak Ridge, TN (1999)

4. "Enhancing the Operation of Highly Varying Industrial Loads to Increase Electric Reliability, Quality, and Economics," (Participants: Northern Indiana Public Service Co., Purdue University, Colorado School of Mines, DOE), Oak Ridge National Laboratory, Oak Ridge, TN, DRAFT (2000)

5. Senate Flips the Switch on Electricity Generation, The Oregonian, Portland, Oregon (April 21, 1999)

6. F. L. Burton, "Water and Wastewater Industries: Characteristics and DSM Opportunities," Burton Environmental Engineering, Los Altos, CA, prepared for the Electric Power Research Institute, Palo Alto, CA (March 1993)

7. B. J. Kirby, E. Hirst, “Ancillary-Service Costs for 12 U.S. Electric Utilities," ORNL/CON-427, Oak Ridge National Laboratory, Oak Ridge, TN, (March 1996)

8. J. S. Gilbert, P.E., CEO, "Market-Flexible Load Shapes," Apogee Interactive Inc., Tucker, GA (1999)

9. "Electric Power Annual 1998, Volume II," Energy Information Administration (EIA), DOE/EIA0348(98)/2, http://www.eia.doe.gov/electricity/epav2/epav2.pdf. Washington, DC, (1999)

10. Siegel, T., Comparison of Curtailable Load Programs, presentation to 2001 Load Participation Stakeholder Meeting, California ISO, Folsom, CA (September 20, 2000)

11. Dunlop, B. and Gilligan, D., The Role of Energy Efficiency and Energy Service Companies in Wholesale Markets, "Proceedings of the American Council for an Energy-Efficient Economy 1998 Summer Study on Energy Efficiency in Buildings," Asilomar, CA (August 21-25, 2000)

12. California ISO. 2000. "Summer 2001 Demand Relief Program," California ISO. Folsom, CA. (October 25, 2000)

13. Fuller, D. Demand Participation, Summer 2001 and Beyond, presentation to 2001 Load Participation Stakeholder Meeting, California ISO, Folsom, CA (September 20, 2000)

14. J. Doudna, "Overview of California ISO Summer 2000 Demand Response Programs" Panel Session on Fast-Acting Load Control For System and Price Stability, IEEE-PES Winter Power Meeting, Columbus, OH (January 28 - February 1, 2001) 
15. Perez, G., Lessons Learned, Summer 2000 Load Programs, presentation to 2001 Load Participation Stakeholder Meeting, California ISO, Folsom, CA (September 20, 2000)

16. Winter, T., "Action Plan to Accelerate Generation, Transmission, and Demand Response in California," California ISO, Folsom, CA. (August 10, 2000)

17. California Public Utilities Commission (CPUC), "Order Instituting Rulemaking into the Operation of Interruptible Load Programs," San Francisco, CA (October 2000)

18. G. A. Heffner, "Review of California's Non-Firm Commercial/Industrial Load-Management Programs", prepared for Lawrence Berkeley National Laboratory (December 5, 2000)

19. California Public Utilities Commission. 2001. Energy Division's Report on Interruptible Programs and Rotating Outages. San Francisco, CA.

20. First-Ever 'Click On' Load Response Program Set to Begin in New England, Business Wire news release, October 31, 2000

21. Operating Procedure 4, Action During a Capacity Deficiency, NEPOOL Operating Procedure, accessible at www.ISO-NE.com

22. Turner, Alasdair, T N Chan, and Alan N Gibbs. "A Fast Reacting Power System Load Shedding Management System. Proceedings of the $9^{\text {th }}$ Conference on the Electricity Supply Industry (CEPSI), Hong Kong, 1992.

23. Ministry of Economic Development of New Zealand. Inquiry into the Electricity Industry. www.electricityinquiry.govt.nz, June 2000.

24. Alvey, Trevor, Doug Goodwin, Xingwang Ma, Dan Streiffert, and David Sun. "A Security Constrained Bid Clearing System for the New Zealand Wholesale Electricity Market." IEEE Transactions on Power Systems, vol 13(2), May, 1998.

25. M-Co. Demand Side Participation - Principles. Discussion paper issued for the 25 July 2000 meeting of the Market Pricing Working Group of NZEM.

26. Siddiqui, Afzal, Chris Marnay, and Mark Khavkin. "Excessive Price Volatility in the California Ancillary Services Markets: Causes, Effects, and Solutions.” Electricity Journal, vol. 13(6), Jul. 2000, also available as LBNL-46083.

27. W. Nesbit, "Utilities install Mega-meter systems," Electrical World, Vancouver, WA (July/August 2000)

28. C. Otero-Goodwin, When You've Gotta Have It: Options for Collecting Interval Data, EIC-8, E Source, Inc., Boulder, CO, www.cellnet.com and Esource (November 1999)

29. "MainStreet Internet Gateway," MainStreet Networks, Morgan Hill, CA, description found at WWW.mainstreetnetworks.com, (December 2000)

30. 4 articles: F. Harvey, The Internet in Your Hands, K. Bannan, The Promise and Perils of WAP, D. Wilson, The Future Is Here. Or Is It?, L. Kahney, The Third-Generation Gap, Scientific American (October 2000)

31. The Wireless Revolution, see archive issue under "Information Technology" heading at chronicle.merit.edu, Chronicle of Higher Education, Washington, DC (October 13, 2000)

32. B. Kiernan, "From RTP to Dynamic Buying: Communications, Analysis, And Control To Tools For Managing Risk," EIC-7 (September 1999)

33. James Boler, personal communications with E source, national energy manager, Dayton-Hudson Corp., Minneapolis, MN (2000)

34. Kirby, B. and Hirst, E., "Retail-Load Participation in Competitive Wholesale Electricity Markets," Edison Electric Institute, Washington, DC, and Project for Sustainable FERC Energy Policy, Alexandria, VA (January 2001)

35. R. Heede, "Home Made Money," Rocky Mountain Institute (1995) 
36. Kirby, B. and Hirst, E. 1999. Load as a Resource in Providing Ancillary Services. Lockheed Martin Energy Research, Oak Ridge National Laboratory. Oak Ridge, TN.

37. Siegel, T. 2000. Comparison of Curtailable Load Programs. Presentation to 2001 Load Participation Stakeholder Meeting. California ISO. Folsom, CA. (September 20)

38. A. Capage, R. Davis, and W. LeBlanc, "The Dawning of Market-Based Load Management," ER99-18. E-Source, Boulder, CO (1999)

39. Dagle, J., Winiarski, D., Donnelly, M. 1997. End-Use Load Control for Power System Dynamic Stability Enhancement. PNNL-11488. Pacific Northwest National Laboratory. Richland, WA. 